\title{
Beyond "Doing as the Romans Do": A review of research on countercultural business practices
}

\author{
Dan V. Caprar ${ }^{1}$, \\ Sunghoon Kim², \\ Benjamin W. Walker ${ }^{3}$ and \\ Paula Caligiuri $^{4}$
}

\footnotetext{
${ }^{1}$ Discipline of International Business, The University of Sydney, Abercrombie Building, Room 4009, Sydney, NSW 2006, Australia; ${ }^{2}$ Discipline of Work and Organisational Studies, The University of Sydney, Abercrombie Building, Room 4185, Sydney, NSW 2006, Australia; ${ }^{3}$ School of Management, Victoria University of Wellington, RH 903, Rutherford House, Lambton Quay, Pipitea, Wellington 6140, New Zealand; ${ }^{4} D^{\prime}$ Amore-McKim School of Business, Northeastern University, 312C Hayden Hall, 360 Huntington Avenue, Boston, MA 2115, USA

\section{Correspondence:}

DV Caprar, Discipline of International Business, The University of Sydney, Abercrombie Building, Room 4009, Sydney, NSW 2006, Australia

e-mail: dan.caprar@sydney.edu.au
}

\begin{abstract}
There has long been a dominant logic in the international business literature that multinational corporations should adapt business practices to "fit" host cultures. Business practices that are congruent with local cultural norms have been advocated as effective and desirable, while practices that are incongruent have been deemed problematic. We examine and challenge this persistent assumption by reviewing the literature showing evidence for both benefits and acceptance of countercultural practices (i.e., practices that are seemingly incongruent with local cultural norms or values), and disadvantages and rejection of local practices. Drawing on the literature reviewed, we offer four types of theoretical (ontological, epistemological, causal, and functional) explanations as to why and when countercultural business practices might be preferred. Finally, we provide a springboard for a future research agenda on countercultural practices, centered around understanding the circumstances under which businesses and local stakeholders might benefit from the use of countercultural practices based on such factors as strategic intent, local preferences, institutional drivers, and social responsibility.
\end{abstract}

Journal of International Business Studies (2022) 53, |449-| 483.

https://doi.org/ | 0. I057/s4 I 267-02 I-00479-2

Keywords: countercultural practices; evaluation of current theories; best practices; cultural impact of MNEs; standardization/adaptation

The online version of this article is available Open Access

\section{INTRODUCTION}

An enduring question for academics and practitioners in international business and management (IB/IM) is how to account for cultural differences when conducting business across borders (e.g., Hutzschenreuter et al., 2011; Kirkman et al., 2006; Newman \& Nollen, 1996; Tsui et al., 2007). The literature has addressed this question as a tension between convergence and divergence of business practices across nations (e.g., Tregaskis \& Brewster, 2006), as a balance between standardization and local differentiation of practices within multinational networks (e.g., Pudelko \& Harzing, 2007), and as a dual imperative of global integration and local
Received: 28 February 2021

Revised: 3 August 2021

Accepted: 27 September 2021

Online publication date: 1 January 2022 
responsiveness of business strategies (e.g., Bartlett \& Ghoshal, 1989).

The fundamental assumption underpinning this research is that fit between business practices and local cultures matters. Following a seminal study by Newman and Nollen (1996) focused on the link between management practices and financial performance, it has been largely argued and accepted that multinational enterprises (MNEs) must adopt practices that are congruent with local cultural norms. In general, principles like alignment and fit have a positive connotation in the field, while misalignment and misfit are often seen as problematic. The argument for fit with local cultures has been formulated in both pragmatic terms (gaining legitimacy, reducing the liability of foreignness, enhancing locals' acceptance; e.g., Jaeger, 1986; Ma \& Allen, 2009; Mezias, 2002; Rosenzweig \& Nohria, 1994) and ethical reasoning (cultural sensitivity as opposed to cultural imperialism; e.g., Calvano, 2008). The discussion of fit also reflects the fact that variation in practices across cultures has been repeatedly observed over time (e.g., Brewster et al., 2004; Lazarova et al., 2008; Schuler \& Rogovsky, 1998). Case studies criticizing organizational and individual failure to conform to local norms and highlighting negative consequences associated with their lack of adaptation are also common in business and management research and education (e.g., Gao, 2013; Meyer, 2015).

While the preference for fit is pervasive in the academic literature, MNEs operating in foreign countries will, at times, for strategic or other reasons, eschew cultural adaptation and intentionally or inadvertently introduce practices that are inconsistent with local cultural norms (e.g., Aguzzoli \& Geary, 2014; Edwards et al., 2016; Mellahi et al., 2016; Nelson \& Gopalan, 2003). Companies will sometimes adapt their products and services to fit their markets, while their management and operations practices may remain rooted in their home cultures. At times, these organizations may become true "cultural incubators" (Caprar, 2011), shaping local norms and values even beyond the boundaries of the organization (e.g., Ritzer, 2018), as they purposefully or incidentally use countercultural business practices.

The use of countercultural practices (i.e., business practices not aligned with accepted local cultural norms), however, is not featured in IB/IM studies as a legitimate topic, and, if mentioned, it is often portrayed as a failure to achieve the ideal state of cultural fit. This failure is attributed to either ignorance (i.e., MNEs being unaware of the need to adapt their practices), difficulties with implementing adaptation (i.e., MNEs are aware of cultural differences, but find it challenging to adapt their tried and tested approaches), consistency with strategic choices (i.e., MNEs pursuing a global or international strategy, as opposed to a multi-domestic or transnational strategy), or managerial incompetence. Yet, by carefully examining studies focused on understanding the role of culture in IB/ IM, one can see that countercultural practices may be less problematic than expected and are even, at times, more effective than local practices. This provides an ironic twist to the cultural fit literature, as empirical studies hypothesizing fit have, instead, found support for the use of countercultural practices. As the studies were designed to test cultural fit, the unexpected results are often considered anomalies in the data. We contend that these "anomalies", collectively, offer an important insight into an existing phenomenon that deserves attention. Not only have some studies found countercultural practices to be used but they have also, at times, found such practices to be beneficial. For instance, in a meta-analysis of the link between high-performance work systems and business performance, Rabl et al. (2014), following the standing wisdom of cultural fit in the literature, predicted that high-performance work systems would be more effective when they fit with national cultural values. What they found was quite different: the relationship between high-performance work systems and business performance was stronger and positive in countries hypothesized to be cultural misfits for this approach. Similar examples of findings that are "puzzling, counterintuitive, and contrary to what the research literature suggests" (Von Glinow et al., 2002: 133) abound in the literature.

With these considerations in mind, we conducted a review of the literature with the specific objective of identifying studies that capture (intentionally or not) instances of countercultural practices, and, in particular, instances where the use of such practices was not problematic, and sometimes, even beneficial. Both anecdotal evidence from practice suggesting that countercultural practices are common, and that multiple studies, reporting evidence that they can even be effective, signaled the need for such a review. We have discovered that countercultural practices are one of those "compelling empirical patterns that cry out for future research and theorizing" and "that, once 
described, could stimulate the development of theory and other insights" (Hambrick, 2007:1350). Indeed, phenomenon-driven research has been highlighted as a priority for the field (Doh, 2015) in the context of ongoing calls for fresh perspectives in IB/IM research (e.g., Buckley, 2002; Buckley et al., 2017; Delios, 2017; Verbeke et al., 2018). Our focus on countercultural practices is consistent with such perspectives, both because this is a phenomenon that exists, yet has not been explored or theorized enough, and because it problematizes a fundamental assumption in the field (Alvesson \& Sandberg, 2011). Problematization (i.e., identifying, scrutinizing, and reconsidering assumptions in the field) opens opportunities to forge new perspectives that prompt fresh research questions, which would otherwise be viewed as illegitimate, if even "viewed" at all.

It seems important to clarify that we are not disputing the value of cultural adaptation: the evidence for the importance of cultural fit is overwhelming (Daniels \& Greguras, 2014; Earley \& Gibson, 1998; Newman \& Nollen, 1996; Schuler \& Rogovsky, 1998; Tsui et al., 2007). However, in light of our observation that the field has accumulated significant empirical evidence showing that countercultural practices can be effective, we argue that the predominant focus on cultural fit precludes us from acknowledging the potential value of misfit under certain conditions. In other words, our work is not meant to dismiss the importance of cultural fit, nor to condone cultural imperialism. In fact, as we show later in our discussion, when multiple stakeholders are properly considered including, for instance, the desire of local employees to depart from certain norms of their own culture (e.g., Caprar, 2011) - what constitutes fit and what is viewed as imposing cultural norms, etc. might change.

The premise of this review is to better delineate the benefits of intentional and considerate use of countercultural practices (instead of wishing them away or treating them as an anomaly undeserving of further exploration). By recasting the literature through a more intentional frame, and by encouraging the inclusion of perspectives that go beyond the interests of the organization, this review aims to make sense of empirical findings that contradict the dominant thinking in the field. This perspective is consistent with the emergent conversation on positive cross-cultural scholarship (e.g., Stahl et al., 2016, 2017): it is meant to bring about a more balanced view on culture, refocusing attention towards generative aspects of international business challenges, as opposed to taking the usual predominantly negative view of differences, diversity, and cultural distance (Stahl \& Tung, 2015). We draw attention to the need to explore countercultural practices as an inevitable (and not necessarily deleterious) reality of IB/IM, and as a phenomenon that could open new avenues for research towards a better understanding of the nuances of conducting business across borders.

It seems important to acknowledge that we emphasize a cultural lens in our review, as opposed to other theoretical lenses that have been used to explore business practices in global operations. Studies informed by neo-institutionalism (e.g., Kostova \& Roth, 2002; Kostova et al., 2008), and comparative institutionalism (Jackson \& Deeg, 2008; Morgan et al., 2010), along with more recent explorations of power relations in the interaction between MNEs in their context (e.g., Geary \& Aguzzoli, 2016), are also revealing instances of both isomorphic and non-isomorphic developments, akin to the cultural adaptation/non-adaptation perspective. Indeed, there is continued discussion around how culture and institutions relate to each other, or which perspective is most useful (e.g., Caprar \& Neville, 2012; Hatch \& Zilber, 2012; Suddaby, 2010). In our review, we acknowledge and discuss the relevance of institutional pressures, but focus on studies that explore business practices in relation to local cultures.

We begin by presenting the review methodology we adopted, which had to be tailored to the peculiar case of looking for research on a phenomenon that is not uncommon, but that has not been properly recognized as a legitimate topic in the field. We then discuss in more detail why the phenomenon of countercultural practices has remained undertheorized and underexplored, despite its relevance to the IB/IM. By exploring the roots of the cultural adaptation imperative and its development over time, we show that suggestions for a more nuanced view on the interplay between culture and business practices have been formulated in the literature all along, just not properly acknowledged. We then present empirical evidence showing that countercultural practices can be effective and welcomed, and related evidence showing that adaptation is not always beneficial. Finally, we develop potential theoretical explanations for such "surprising" findings, demonstrating that they can be explained and utilized for refining and further developing theory in IB/IM. 
We conclude with implications for theory and practice, setting up the foundation for a research agenda on countercultural business practices.

\section{REVIEW METHODOLOGY}

Conducting a review of studies focused on countercultural practices in a field largely informed by the imperative for cultural adaptation required a particular approach: the field has not yet recognized the focus on this phenomenon as a topic of investigation, and, as such, researchers have not deliberately pursued it. Yet, as mentioned before, many studies have inadvertently detected instances of countercultural practices. Our task was to identify these studies despite the countercultural focus not being clearly signaled. Consequently, our review approach unfolded in two phases: a scoping phase and a focused phase.

In the scoping phase, we first identified seminal articles related to the topic of cultural adaptation and its variants (i.e., convergence/divergence, differentiation/integration, localization/standardization/contextualization). We searched for articles that both presented evidence of use and impact of countercultural practices and articles providing insights into why the need to achieve fit has become "almost axiomatic" (Lawrence \& Lorsch, 1986: xii), despite not always being the only (let alone best) approach in practice (e.g., Caligiuri $\&$ Tarique, 2016). The seminal articles came to our attention through various avenues: scanning major journals in the field; receiving recommendations from colleagues; examining the articles cited in identified articles; and following up with new content alerts from journals, to name but a few. This scoping phase provided us with indications as to where (i.e., what journals) and how (i.e., what keywords) we would need to search for more literature on countercultural practices. Moreover, these additional empirical studies, theoretical and conceptual articles, literature reviews, and scholarly essays were helpful in elucidating the broader research context surrounding the focus of our review. Specifically, such articles allowed us to begin building an understanding of why exactly countercultural practices have long been "missing" in IB/IM research. An understanding of the drivers of this absence is crucial if, as we indeed argue later, more research will emerge on countercultural practices in the future.

In the focused review phase, we identified relevant empirical research in leading scholarly journals. One advantage of such an approach over others (e.g., broad searches using Google Scholar) is the ease of quality control over the research being reviewed. We selected journals taking into consideration the high impact journal list conventionally recognized in recent review articles (e.g., Aguilera et al., 2019), widely accepted journal ranking systems, such as the Financial Times 50 list, and the rankings provided by the Australian Business Deans Council. We ultimately derived a list of 23 relevant journals to include in our search through this process, including leading IB journals (Journal of International Business Studies, Journal of World Business, Journal of International Management, Management International Review, Journal of International Business, Global Strategy Journal, International Business Review), leading management journals (Academy of Management Journal, Human Relations, Journal of Applied Psychology, Journal of Management Studies, Strategic Management Journal, Journal of Management, Journal of Business Ethics, Organization Science, Organization Studies, Administrative Science Quarterly), HRM specialty journals (Human Resource Management, International Journal of Human Resource Management, Asia Pacific Journal of Human Resources), and cross-cultural management journals (Journal of Cross-Cultural Psychology, Cross Cultural \& Strategic Management, International Studies of Management \& Organization). We searched each journal for articles containing keywords that could be related to countercultural practices, such as: cultural adaptation; localization; liability of foreignness, liability of localness, asset of foreignness, advantage of foreignness, disadvantage of localness; cultural sensitivity; countercultural; contextualization; local adaptation; cultural distance; cultural friction; cultural change; cultural imperialism; local culture; and local legitimacy. In terms of timeframe, we limited our search to articles published between 1980 and 2020. We chose 1980 as the lower threshold for our search as this was the year in which Hofstede's (1980) seminal work on crosscultural management was published, which subsequently triggered a wave of research on issues of national culture in and around organizations.

At the conclusion of this process, we had identified a total of 95 empirical studies relevant to our exploration. Of these, 22 articles provided direct evidence that countercultural practices can be beneficial (Table 1). Another set of 18 studies captured situations where countercultural practices were found to be accepted or even preferred by locals (Table 2). During our search for articles 
Table 1 Empirical studies documenting benefits of countercultural practices

\begin{tabular}{ll}
\hline References & Sample/context \\
\hline $\begin{array}{l}\text { Erez and Earley } \\
\text { (1987) }\end{array}$ & $\begin{array}{l}120 \text { Israeli university students + } 60 \text { US university } \\
\text { students }\end{array}$ \\
$\begin{array}{l}\text { Bonache } \\
\text { (1999) }\end{array}$ & $\begin{array}{l}6 \text { representatives from a US consulting firm tasked with } \\
\text { implementing an employee idea suggestion program in } \\
\text { an MNE with operations in Brazil, Mexico, Portugal, } \\
\text { Canada, and the US }\end{array}$
\end{tabular}
Summary of findings

While US culture is often assumed to be highly individualistic and low on collectivism, US students performed better on the experimental task when goals were participatively set by a group (rather than being assigned to each student individually)

An employee idea suggestion program initially developed and used in US worked even better in the MNE's international subsidiaries. This was true even among those subsidiaries operating in cultural contexts typically perceived as high in power-distance, and despite the program being virtually unchanged from the version used in the US

Robert et al. Employees of a US MNE working in the US $(n=210)$, (2000) India $(n=82)$, Mexico $(n=127)$, and Poland $(n=143)$

Contrary to the authors' predictions, empowerment was found to be positively associated with job satisfaction in Polish and Mexican samples, a surprising finding given that both are typically viewed as high power distance cultures

Bloom and 460 US companies

Michel (2002)

The authors proposed and found support for the notion that more compressed pay dispersions in organizations generate a more egalitarian environment (i.e., signal that all managers are important, irrespective of comparative performance), which in-turn results in better managerial retention. Their findings support this logic, despite data being obtained from companies operating in the US, which is typically viewed as a highly individualistic culture where egalitarianism is generally viewed unfavorably

Gong (2003) 400 top management teams of foreign subsidiaries of 28 Japanese multinational enterprises Filling leadership positions with parent- (rather than host-) country nationals was associated with higher labor productivity among foreign subsidiaries of Japanese MNEs. Additionally, this positive effect was stronger the more culturally distant the foreign subsidiary

Chang (2006) Employees of Korean companies across many industries Individual pay-for-performance was found to have a positive impact on the self-reported work effort of employees in South Korea, despite it typically being viewed as a highly collectivist culture. In addition, this increase in effort was found not to come at the expense of lower organizational commitment. Moreover, when used as part of a bundle of "commitment HR practices" (e.g., providing employees with training opportunities and long-term job security), individual pay-forperformance was found to be positively associated with both work effort and organizational commitment Western human resource management practices (e.g.,

Gamble (2006) UK-invested retail firm in China highly formalized rules and policies, ability-based rather than seniority-based promotion) produced positive employee responses in China and functioned as a competitive source of differentiation to attract highquality local employees and make them engaged in the workplace 
Table 1 (Continued)

\begin{tabular}{ll}
\hline References & Sample/context \\
\hline Gaur et al. & 12,997 subsidiaries of 2,952 Japanese firms
\end{tabular}

(2007)

Humborstad

et al. (2008)

290 service workers in Macau hotels

Du and Choi

(2010)

Parnell (2010)

218 Mexican and 270 Peruvian managers enrolled in post-graduate training programs

Chen et al., (2011a)

Schotter and Beamish (2011)

2 studies: undergraduate students at a US + Undergraduate students at a Chinese university (Study 1); 144 leaders enrolled in leadership development courses taught by a large public U.S. university in the United States and in China (Study 2)

2,315 subsidiaries of Japanese MNEs in China established between 1990 and 2001

Fock et al. (2012)

Four surveys of frontline retail employees in China and Canada

Hoffman and

Shipper (2012)

13,480 managers (across 50 countries) who participated in a management development program in a large multinational firm

Fisher (2014) 6,264 employees of a single MNE, working at 337 different work locations across 18 countries
Summary of findings

Filling leadership positions with parent- (rather than host-) country nationals was found to have a stronger positive impact on labor productivity the larger the normative institutional distance between home country (Japan) and host country

The practice of giving employees discretion is typically viewed as contrary to Chinese norms of high power distance. Yet the authors found that employee empowerment had a significant positive impact on employees' willingness to deliver quality service The authors predicted that Chinese workers, due to their collectivistic cultural values, would react negatively towards pay based on individual performance. However, they could not find good support for such a hypothesis. Instead, authors found that individualistic pay practice may enhance Chinese employees' work attitudes Although Peruvian work cultures do not typically encourage subordinate participation in managerial decision-making, and Peru has a history of strong authoritative leadership, Peruvian managers working in more participative organizational cultures were found to be more committed to their organizations than those working in less participative organizational cultures Empowering leader behaviors directed at a team as a whole (as distinct from any single individual) were found to have a stronger positive effect on psychological empowerment for individuals from the US (a less collectivistic culture) relative to individuals from China (a more collectivistic culture)

Among subsidiaries operating in provinces with high foreign direct investment legitimacy, the employment of expatriate (versus local) general managers was found to be positively associated with subsidiary performance Leadership empowerment (leadership behaviors that facilitate employee performance by enabling and encouraging employees in their work roles) had a positive direct effect on job satisfaction, and, surprisingly, this effect was stronger among employees with higher power distance values

Even among employees working in cultures of low-tomoderate (as well as high) power distance, a controlling/dominating style of leadership was found to be positively associated with employees' affective commitment

Even among those working in highly individualistic cultures, the perception of a cooperative climate (i.e., that employees can count on their coworkers for assistance and that there is a spirit of cooperativeness among colleagues) was found to buffer the negative effect of role overload on organizational commitment 
Table 1 (Continued)

\begin{tabular}{ll}
\hline References & Sample/context \\
\hline Rabl et al. & Meta-analysis of 56 high-performance work system- \\
(2014) & $\begin{array}{l}\text { business performance effect sizes from 35,767 firms and } \\
\text { establishments in } 29 \text { countries }\end{array}$
\end{tabular}

Summary of findings

High-performance work systems (e.g., selectivity in staffing, investments in training, pay for performance, employee participation in decisions) were found to have a positive effect on business performance in all countries included in the analysis. Contrary to the authors' initial predictions, this positive effect was strongest in countries high on the cultural dimensions of power distance and collectivism

jiang et al. $\quad 260$ facilities of a US-based MNE across 22 countries (2015) Involvement work systems (a bundle of work practices comprising information-sharing, participation in decision-making, and team-based work design) was found to have a stronger positive effect on operational effectiveness in higher power distance cultures

Colakoglu et al. 45 US-owned MNEs and 61 local firms operating in (2016) Bangladesh In Bangladesh, where local cultural norms typically dictate an autocratic and control-oriented human resource (HR) approach, the authors found that adopting a high-investment HR approach (i.e., treating employees as valuable assets worthy of organizational investment) was associated with better performance for both domestic and foreign-owned firms

Rao and Pearce 1,347 employees and managers of an MNE located (2016) across seven countries. The majority of respondents were currently working in India (74.3 percent) and the USA (9.8 percent)

In the high power distance cultural context of India, supervisors who practiced empowerment, consultation, and information exchange had employees who reported better team collaboration, innovation, and future team performance than supervisors who acted to increase their subordinates' dependence on themselves Despite China typically being perceived as a highly collectivistic culture, human resource practices that recognize individual-level performance were found to have a positive impact on employees' perceived levels of organizational support

Mayes et al. 190 managers and employees of a Chinese hotel (2017)

Siegel et al. (2019)
Nationally representative firm-level data from South Korea
In South Korea's masculine culture, foreign multinational companies were found to demonstrate improved profitability and productivity when they engaged in the countercultural practice of aggressively hiring more female workers and promoting them to leadership positions related to countercultural practices, we also identified studies capturing negative consequences or perceptions of local(ized) practices (14 studies; Table 3). We have included these studies in our review as they also support the need to think critically about the efficacy of cultural adaptation, and the importance of giving more attention to countercultural practices. The remaining 41 studies, while not directly addressing the benefits or acceptance of countercultural practices (or the disadvantages/rejection of local practices), were relevant in terms of capturing a broader related argument suggesting that foreignness is not always a liability, or that localness is not always an advantage. We discuss these articles in more detail in the section on empirical evidence. It is also important to note that at least some results supporting the use and effectiveness of countercultural practices are most likely never reported: studies with results that disconfirm formulated hypotheses (which are usually built on, and consistent with, existing perspectives) are not usually published (Rosenthal, 1979). The fact we were able to identify such a significant number of articles on the success of countercultural practices provides further justification for greater attention to this topic.

Before describing the specific pieces of empirical evidence collated through our review, we first 
Table 2 Empirical studied documenting acceptance of/preference for countercultural practices

References Sample/context Summary of findings

Singh (1990) 176 managers in India

Chen (1995) Employees from 2 US companies and 3 Chinese stateowned enterprises

Selmer

(1996)

Nyambegera

et al. (2000)

Lowe et al. (2002)

Manages and engineers from 9 countries (Australia, Canada, China, Indonesia, Japan, Korea, Mexico, Taiwan, US)

Fadil et al.

He et al.

Chiang and (2004) (2004)

Chiang (2005)

Participants from Canada $(n=378)$, Hong Kong $(n=252)$, Finland $(n=189)$ and UK $(n=186)$ 441 employees from Hong Kong and Finland

Managers and human resource professionals from a variety of public and private sector organizations in the US $(n=98)$ and Northern Mexico $(n=77)$

297 Chinese employees of Chinese state-owned enterprises

Birtch (2006)
In India (categorized as high power distance by Hofstede), most managers (74\%) preferred to work under a consultative rather than authoritative supervisor. Indian managers also reported that their subordinates are not afraid to express disagreement with them

Contrary to the traditional view that collectivistic Chinese workers prefer an egalitarian reward system, while individualistic Americans prefer differential allocation of rewards, the author found the reverse: Chinese employees preferred differential reward allocation, while Americans preferred equality rule for reward allocation Hong Kong managers were found to prefer the management style of expatriates over locals. The leadership behavior of US bosses was most preferred, followed by that of (in order of preference) British managers, Japanese managers, and other Western managers. Surprisingly, Asian managers were rated as having the least preferred leadership style In the collectivistic society of Kenya, employees preferred a reward system that emphasized individuals' contribution and market-based wage determination. Workers from the US (an individualistic culture) showed a stronger preference for pay based on group/ organizational performance relative to those from most other countries in the sample, including countries typically viewed as highly collectivistic (e.g., China, Korea, Japan). In addition, participants from China, Latin America, Mexico, and Taiwan showed some of the strongest preferences for pay based on individual performance, a surprising finding given that such contexts are typically viewed as collectivistic Much like the US participants, and despite their supposedly collectivistic orientation, the Mexican participants closely followed an individualistic, "pay-forperformance" logic in distributing rewards on the experimental task.

Contrary to earlier studies suggesting a preference for egalitarian work arrangements among Chinese, reform of the ownership and structure of Chinese state-owned enterprises led Chinese workers to prefer differential rather than equalitarian reward allocation Even in the more masculine and individualistic cultural contexts studied, intrinsic rewards were valued more highly by respondents than financial rewards. In addition, even among respondents from Hong Kong (a culture typically viewed as highly collectivistic), pay based on individual performance was found to be valued more than pay based on team or organizational performance Employees from Hong Kong (a high power distance culture) were found to prefer performance-based pay to seniority-based pay. In addition, employees from Finland (a feminine country) were found to show a strong need for achievement-oriented pay 
Table 2 (Continued)

\begin{tabular}{ll}
\hline References & Sample/context \\
\hline $\begin{array}{l}\text { Varma et al. } \\
(2006)\end{array}$ & \\
$\begin{array}{l}\text { Bozionelos host-country nationals in the US and India } \\
\text { and Wang } \\
(2007)\end{array}$ & $\begin{array}{l}106 \text { full-time, white-collar workers in a Chinese state- } \\
\text { owned company }\end{array}$
\end{tabular}

Chiang and Respondents $(n=1,005)$ drawn from the banking

Birtch (2007) industry across 4 countries (Canada, Finland, Hong Kong China and the UK)

Gong (2009) Online shopping data from 58 countries

Mellahi et al. 200 employees and managers across 7 Indian small and (2010)

Lee et al. (2011)

Employees in the banking industry: 232 from Finland, 336 from Hong Kong.

Vo and

Hannif

5 US MNEs operating in Vietnam

(2013)

Yousfi (2014) 27 employees (managers and workers) in the largest business group in Tunisia
Summary of findings

Despite the gender-discriminant local culture, Indian employees were found to prefer working with female expatriates over male expatriates

Contrary to the authors' hypothesis, Chinese workers were found to have positive attitudes towards individually-based performance reward systems, and negative attitudes towards equality-based reward systems (i.e., where all parties are offered equal proportions of rewards regardless of their comparative contributions) Workers in Finland (a highly individualistic culture) were found to prefer group-based incentives more than workers in Hong Kong (a collectivistic culture) Uncertainty avoidance was found to have a significant positive impact on the adoption of $\mathrm{B} 2 \mathrm{C}$ e-commerce (i.e., online shopping). This surprised the author because online shopping is typically viewed as a riskier form of consumption, which would seem to be more accepted in cultures with low (not high) levels of uncertainty avoidance

Despite workers operating in the high power distance context of India, the authors found that the more employees exercised voice, the more (not less) committed they were to their organizations. This finding suggests that the use of voice was viewed favorably by Indian workers

Despite the traditional view of Japan as a high power distance and seniority-centric culture, Japanese employees were found to prefer performance-based pay over traditional seniority-based pay.

Relative to Hong Kong workers, Finnish workers deemed group-based (rather than individual-based) rewards to be more effective. This finding is surprising given that Finland is typically understood to have a more individualistic culture than Hong Kong

Vietnamese culture is typically viewed as conflict averse, and not conducive to open discussions of opposing views. However, the findings show that Vietnamese employees were highly receptive to the more participative leadership styles that were typical within the US MNEs they worked for

Local managers of the largest Tunisian private company used the US management model to overcome the traditional dysfunctional family-based organizational system, and the historical influence of the French colonial model. While they contextualized some practices, they expressed very positive views about the American model, indicating that workers also welcomed the model 
Table 3 Empirical articles documenting negative consequences/perceptions of local(ized) practices

\begin{tabular}{ll}
\hline References & Sample/context \\
\hline $\begin{array}{l}\text { Chen et al. } \\
\text { (2004) }\end{array}$ & Managers enrolled in part-time MBA programs in China \\
Warren et al. & $\begin{array}{l}2 \text { studies: } 203 \text { participants from a school in a large city in } \\
\text { (2004) }\end{array}$ \\
& $\begin{array}{l}\text { Mainland China (Study } 1 \text { ); } 195 \text { graduate business students } \\
\text { in China (Study 2) }\end{array}$
\end{tabular}
Summary of findings

In China, where guanxi is an embedded cultural norm, guanxi-based HR practices were shown to have a negative impact on employees' trust in management Quantitative data show that Chinese respondents differentiated between the effects of guanxi on managers, organizations, and the community, and that the perceived harmfulness and helpfulness of guanxi in any given instance varied depending upon the contextualization. Qualitative data show that Chinese respondents perceive guanxi as having a range of both helpful and harmful consequences in different circumstances and for different parties

Collinson 2 organizations in Japan; 22 interviews with managers, and Wilson technical and engineering personnel, and researchers

(2006)

Boutilier 8 university-educated knowledge workers from the city of (2009) Cuernavaca (Mexico)

Chen et al. 342 employees from 72 workgroups across several (2011b) organizations in China

Peng and Tjosvold (2011)

Yanadori

US R\&D teams

and Cui

(2013)

Yousfi

(2014)

Largest business group in Tunisia; 28 interviews with managers and workers

Goby (2015) Local workers in the United Arab Emirates

Chen et al. MBA students from Brazil $(n=97)$, China $(n=169)$, and (2017) US $(n=139)$
Contrary to dominant perspectives emphasizing the benefits of the archetypal features of Japanese organization, the authors found these features to lead to organizational inertia and performance decline of Japanese organizations

Interviews revealed a perception across the interviewees that nepotism was a common and ultimately unfavorable practice in Mexican-owned and -operated businesses. The author suggests that this may be the result of a strong familial orientation in Mexican culture Having managerial decisions systematically based on guanxi can have a negative impact on employees' procedural justice perceptions; it can also enhance the employees' self-focus, countering the expected positive effect of guanxi at interpersonal level

The Chinese emphasis on social face was more salient when Chinese employees experienced conflict with Chinese managers relative to Western managers. This in turn resulted in Chinese employees being inclined to engage in passive aggressive behavior more with Chinese managers than with Western managers In a national context typically characterized by high individualism (the US), pay dispersion within R\&D teams was found to be negatively related to firm innovation

Local managers of a large Tunisian private company described the paternalistic, family-based management model typical in Tunisian companies as dysfunctional, due to managerial favoritism and corruption Canvasses the employment and work-related challenges faced by local employees in the United Arab Emirates arising from the emergent norm of Emirati companies relying on foreign labor. A key finding is that local employees have experienced a gradual erosion in employment opportunities, work conditions, and benefits due to the "lowering of the bar" triggered by Emirati companies' access to foreign labor Although Brazilians and Chinese report stronger cultural norms of relational favoritism (e.g., nepotism) than Americans, Brazilian and Chinese managers perceive more negative consequences of relational favoritism relative to American managers 
Table 3 (Continued)

\begin{tabular}{ll}
\hline References & Sample/context \\
\hline Azungah & 37 managers and employees across 8 subsidiaries of British, \\
et al. (2018) & European and US MNEs in Ghana
\end{tabular}

Summary of findings

Ghanaian managers are reported as having an authoritarian style (consistent with the high power distance nature of Ghanaian national culture), which was found to inhibit employees' propensity to be transparent and open with their managers during performance management activities

Li et al. Indian participants recruited via MTurk: 202 participants (2020) (Study 1) and 84 participants (Study 2) Among Indian consumers, a (fictional) global brand's localized communication using a highly symbolic Indian cultural element (The Ganges) was found to result in less (not more) favorable reactions toward the brand (i.e., in terms of purchase intention, cognitive evaluation, and affect toward the brand)

Prince et al. A subsample from the 2009 CRANET database, comprising (2020) 2,719 private-sector firms across 19 countries

Contrary to the authors' prediction, the use of bonus payments linked to individual performance was found to have a detrimental impact on turnover and firm performance among firms operating in cultures with a strong performance orientation. The same finding emerged in respect of the individualism dimension of culture

Yang et al. 189 Chinese employees nested in 42 groups

Despite guanxi being an embedded norm in Chinese culture, guanxi-based HRM was found to have a negative impact on employee outcomes (specifically emotional exhaustion and job performance), especially when combined with individual performance pay

present a broader discussion of the evolution of the cultural adaptation tenet in the field, which helps to explain why the phenomenon of countercultural practices has not been recognized as a focal topic of inquiry in IB/IM. This discussion is important to make sense of the empirical findings, which we present in the subsequent section, and for developing a research agenda focused on countercultural practices, which we do towards the end of this article.

\section{THE RISE OF THE CULTURAL ADAPTATION IMPERATIVE}

To understand why the phenomenon of countercultural practices has not been explored as a legitimate topic in IB/IM, a useful point of departure is evaluating the theoretical context (i.e., paradigms) dominating the field. Researchers are typically incentivized to present "incremental enhancements of wide-spread beliefs" (Starbuck, 2003: 349), and, as a result, new research tends not to depart too much from accepted mainstream thinking on any given topic (see also Kuhn, 2012 [1962]). Alvesson and Sandberg (2011) argue that researchers typically generate new theory by spotting or constructing gaps in existing theories - that is, exploring opportunities to extend existing understandings, which precludes an exploration of the underlying assumptions of such understandings - the "hidden" taken-for-granted perspectives that inform, and limit, the theorizing in a domain. Such assumptions can operate at different levels: they can be shared within a particular school of thought, they can manifest as broader metaphors about a particular object of study, or even at the level of paradigms, ideology, or fields of study. They are typically hidden (i.e., implicit and unspoken), but highly consequential in shaping research perspectives (Slife \& Williams, 1995). Yet, by problematizing such assumptions (i.e., identifying, scrutinizing, and reconsidering them; cf. Alvesson $\&$ Sandberg, 2011), new research questions emerge in relation to "blind spots" in a particular field. In IB/IM, the cultural adaptation imperative is based on a broader field assumption that fit is inherently beneficial. We begin by exploring this assumption about the positivity of fit (and the theories that are built around it) in more detail as an explanation for why researchers to date have focused so intently on cultural adaptation, rather than acknowledging 
and studying countercultural practices. We then explore in detail the development of the cultural adaptation imperative, as this further explains why the phenomenon of countercultural practices has become something of a research "blind spot", despite, as we show later, evidence suggesting both its occurrence and potential effectiveness.

\section{The Overall Preoccupation with Fit in IB/IM}

The need to achieve fit is "almost axiomatic" in business and management theories (Lawrence \& Lorsch, 1986: xii). Grand management theories, such as population ecology theory (Van de Ven, 1976), contingency theory (Donaldson, 2001), and institutional theory (Scott, 2001), are all in some way connected to the fundamental notion that organizations must fit their environments to survive. Similarly, specific key IB theories, such as the internationalization of the firm, have for a long time highlighted the liability of foreignness (e.g., Zaheer, 1995). The word "liability" primes research to focus on the negative consequences of being culturally different, a challenge to be overcome. And while recently this focus has been challenged (e.g., Edman, 2016a; Taussig, 2017), these theories have promulgated an implied assumption that fitting with cultural norms is beneficial; a development that has left less theoretical oxygen for the possibility that countercultural practices may be effective and preferred under certain circumstances.

Given our focus on countercultural practices, when we use the term "fit" we refer to consistency between business practices (broadly defined) and local cultures, rather than other uses of the term, such as organizational internal consistency, or fit between strategic choices and internal or external organizational environments in general. However, we provide a brief overview of relevant theories, that have fueled a preoccupation with fit in general, as relevant to understanding the context of the more specific cultural fit imperative.

We begin with the population ecology theory. With roots in the Darwinist "survival of the fittest" perspective, the theory suggests that some varieties of organization survive (while others become extinct) through a natural selection process like that seen in nature. Surviving populations of organizations are believed to be those that adapt best to the demands of their environment (Hannan \& Freeman, 1977), with such adaptations assumed to explain both the variety and the similarity of surviving organizational forms. Contingency theory has also emphasized the need for a multiplicity of organizational forms, with no one best way to manage, but rather, a variety of approaches adjusted to the internal and external environments of the organization (Donaldson, 2001). The essence of the argument made by contingency theorists was that organizational structures that fit such contingencies produce better organizational outcomes. Institutional theory, although often portrayed to be at odds with contingency theory (Meyer \& Höllerer, 2014), also promotes the fundamental principle of fit, suggesting that organizations must attain social legitimacy by adopting managerial practices that are taken for granted by other organizations in the same field (Meyer \& Rowan, 1977). Specifically, DiMaggio and Powell (1983) suggested that organizations are pressured to adopt practices that are legitimated by coercive, mimetic, and normative mechanisms.

Given the prevalence of a functionalist view of fit in such organizational theories, it is unsurprising that this perspective has also come to underpin much of the thinking about how to optimize international operations. For instance, in an evaluation of the environments of MNEs, Rosenzweig and Singh (1991) emphasized the need for MNEs to adapt to the local environment, adaptation that goes beyond coercive isomorphism dictated by local regulations and economic pressures: it is posited that MNEs must also reflect values, norms, and local practices (Westney, 1993), which are, obviously, the expression (and constituents) of the local culture.

The specific analysis of the adoption of organizational practices by subsidiaries of MNEs also revealed institutional effects imposed by characteristics of the host countries (Kostova \& Roth, 2002). Zaheer (1995) argued that MNEs inherently suffer from a deficiency in local legitimacy due to what the MNE literature describes as the liability of foreignness (Hymer, 1960/1976). To compensate for the disadvantage of being foreign, Zaheer (1995) recommended that MNEs should imitate local firms, as conforming to local isomorphic pressures should enhance local legitimacy. Progressively, the field has embraced the premise that foreignness is a liability, and that this liability can be overcome by imitating local firms (e.g., Salomon \& Wu, 2012).

These are just a few examples of the many arguments in the field that essentially praise congruence as beneficial and label misfit as problematic. Moreover, when applied to the global context (i.e., MNEs), foreignness is cast as a largely inescapable source of misfit. While these arguments were typically formulated at the organizational level, their influence on defining business practices in general 
has been pervasive. We next detail the manifestation of the fundamental fit assumption in IB/IM.

\section{The Cultural Adaptation Imperative}

In this section, we trace the development of the cultural adaptation imperative in IB/IM, showing that it has a achieved a dominant position for legitimate reasons. Unfortunately, such dominance, bolstered by the aforementioned positive outlook on fit in general, has crowded out the potential for a concerted research focus on countercultural practices.

\section{Historical thinking on global business practices}

Early theorizing about effective practices across cultures did not argue in favor of local adaptation. On the contrary, the economic development of highly industrialized (i.e., "Western") economies, and a general tendency for a self-referential perspective on culture, prompted researchers from the developed world to formulate the recommendation that other countries should "evolve" towards a similar economic philosophy. For instance, initial comparisons of management approaches in Japan and the US concluded that the Japanese approach was inappropriate, simply because it did not comply with Western principles (Harbison, 1959). Such a statement nowadays would be deemed ethnocentric, but at that time it had a powerful influence on thinking in the field, setting up a conversation about the need for, and indeed inevitability of, convergence in business practices (e.g., Kerr et al., 1960). The later success of Japanese companies (Vogel, 1979), along with early comparative management studies (e.g., Gonzalez \& McMillan, 1961; Oberg, 1963) challenging the universality of Western (i.e., American) approaches, made room for an alternative view, that practices consistent with cultural traditions (i.e., divergent) were not necessarily flawed, and may even be superior to a standardized Western model (Abegglen, 1973).

It did not take long, though, for researchers to move away from such exclusive perspectives and recognize potential benefits in both views. Three ideal types of organization were conceptualized based on the original contrasting American and Japanese models (Ouchi \& Jaeger, 1978): Type A (North American and Western European), Type J (Japanese and Chinese), and the mixed Type Z (a modified American model with influences from Type J). The latter type was presented as more appropriate even for the American context, suggesting the potential value of countercultural practices: the model showed that some Japanese practices were appreciated and well regarded by American workers and managers. Although not directly stated as such, we identify the Type $\mathrm{Z}$ organization as an early attempt to focus on identifying best practices, where (not) adapting to the local culture was not the driving criterion. A detailed review of the debate applied to the evolution of the Japanese management concluded that the best feature of the Japanese approach was being "a flexible, innovative process of choice; it is understood that cultural values are only one important factor in achieving goals" (Dunphy, 1987: 454). This characterization seems to summarize very well what, later, Ralston et al. (1993) defined as "crossvergence", a perspective that clearly attempted to reconcile the convergence (standardization) and divergence (localization) perspectives. The concept was further developed in subsequent studies including one that won the Journal of International Business Studies' 2007 Decade Award; for an overview, see Ralston 2008), but the imperative for cultural adaptation continued to be reflected in most IB/IM studies, including those who cite this prominent work.

\section{The cultural turn}

The conversations around convergence and divergence of business practices were paralleled by increasing interest in cultural specificity (Laurent, 1986), an interest that perhaps can be attributed to Hofstede's (1980) extremely popular study on culture's consequences, which emphasized differences in national cultures. A coherent model of cultural fit was soon proposed (Kanungo \& Jaeger, 1990; Mendonca \& Kanungo, 1994), emphasizing the importance of the socio-cultural environment in defining an organization's work culture and related human resources practices. An avalanche of theoretical models and empirical results followed that advocated the idea of fit between business practices and national cultures. For instance, Earley (1994) suggested in an experimental study that groupfocused training would be more effective for collectivistic individuals, while self-focused training would be more effective for individualistic people. Kirkman and Shapiro (1997) proposed that the success of self-managing work teams in foreign subsidiaries may depend on how MNEs effectively reduce the culture-based resistance of local employees. Chen et al. (1998) also suggested that organizations are likely to effectively foster cooperation within a firm when organizational arrangements are well aligned to employees' cultural values. 


\section{From cultural sensitivity to cultural imperative}

As evidence supporting the idea of cultural fit accumulated, researchers returned to testing the earlier model of cultural fit, further emphasizing the relevance of culture to business and management (e.g., Aycan et al., 2000). However, the study that seemed to have shaped the thinking in the field, often cited by most studies related to the topic, is the seminal piece by Newman and Nollen (1996): they directly tested the overall relationship between management-culture fit and performance, concluding that business performance is superior when management practices are congruent with the national culture. Consequently, they unequivocally recommended that management practices must be adapted to local cultures, a view that became central to the field of IB/IM. It is worth noting that Newman and Nollen's (1996) study has been cited much more often in comparison to the earlier articles (e.g., Dunphy, 1987; Ouchi \& Jaeger, 1978) proposing a more complex approach to culture fit.

Recent insights related to cultural adaptation. Pudelko and Harzing (2007) explored the presence of fit in a study of human resource management (HRM) practices in foreign subsidiaries. Using a large-scale sample of multinationals originating in the US, Japan, and Germany, along with their subsidiaries in these countries, Pudelko and Harzing (2007) tested the two dichotomies of HR practice implementation: convergence versus divergence, and standardization versus localization. In their study, standardization is the implementation of the convergence perspective, and localization reflects the divergence view. They further delineated standardization in two ways. One is the country of origin effect, which emphasizes the importance of maintaining headquarters' practices across subsidiaries globally. The other is the dominance effect, in which "global" (often USbased) best practices are implemented around the world. While the country of origin and the dominance effects are both versions of standardization (and, therefore, in opposition to localization), the prevalence of the dominance effect implies the existence of global best practices. In addition, the dominance effect was also found to be increasing over time among the organizations studied. Research has also concluded that certain HRM practices are more likely to be bound to nationallevel institutional forces, requiring a higher level of divergence across countries, whereas other HR practices can be adopted similarly across countries, enabling convergence (Farndale et al., 2017).
The aforementioned findings provide especially useful insights into which HRM practices will likely vary across subsidiaries and which will be standardized. However, these findings do not allow for inferences regarding why the converging dominance effect is observed more often (and increasing over time), and implicitly does not allow for theory-based prescriptions. Moreover, the fact that dominance is stronger, and convergence is present, does not necessarily highlight the fact that these might be positive developments. However, based on the observation that most local subsidiaries converge towards a dominant model, Pudelko and Harzing (2007) concluded that "there is less need to localize than frequently believed" (2007: 553). We acknowledge this insight as critical, and consistent with our view that the cultural fit imperative needs to be explicitly challenged and better investigated for strategic nuances to emerge.

Empirical evidence of countercultural practices While $\mathrm{IB} / \mathrm{IM}$ theory evolved towards confirming the need to adapt practices to local contexts, many companies have continued doing what they know best: implementing practices that work in their home countries (standardization by the country of origin effect), or practices thought to be universally effective (standardization by dominance). Whether such approaches are intentional or just a result of inability (or unwillingness) to adapt is not the focus of our investigation. What is important is that such practices represent a reality of global business that remains largely unexplored in the field.

It seems important to reiterate that the empirical evidence supporting the use of countercultural practices shows up (most often "uninvited") in studies aimed at validating the cultural fit imperative. In such studies, researchers sometimes serendipitously capture surprising findings: the expected positive effect of culturally congruent practices are not confirmed, while approaches that could qualify as perfect cases for "what not to do" do not have the expected detrimental outcome and may even have positive effects. Overall, the accumulated findings (summarized in Figure 1) suggest that the cultural adaptation imperative needs to be scrutinized, or at least supplemented with additional perspectives, which is an opportunity to further develop our understanding of the role of culture in international business, and to better define what constitutes "effective" IB/IM practices. 


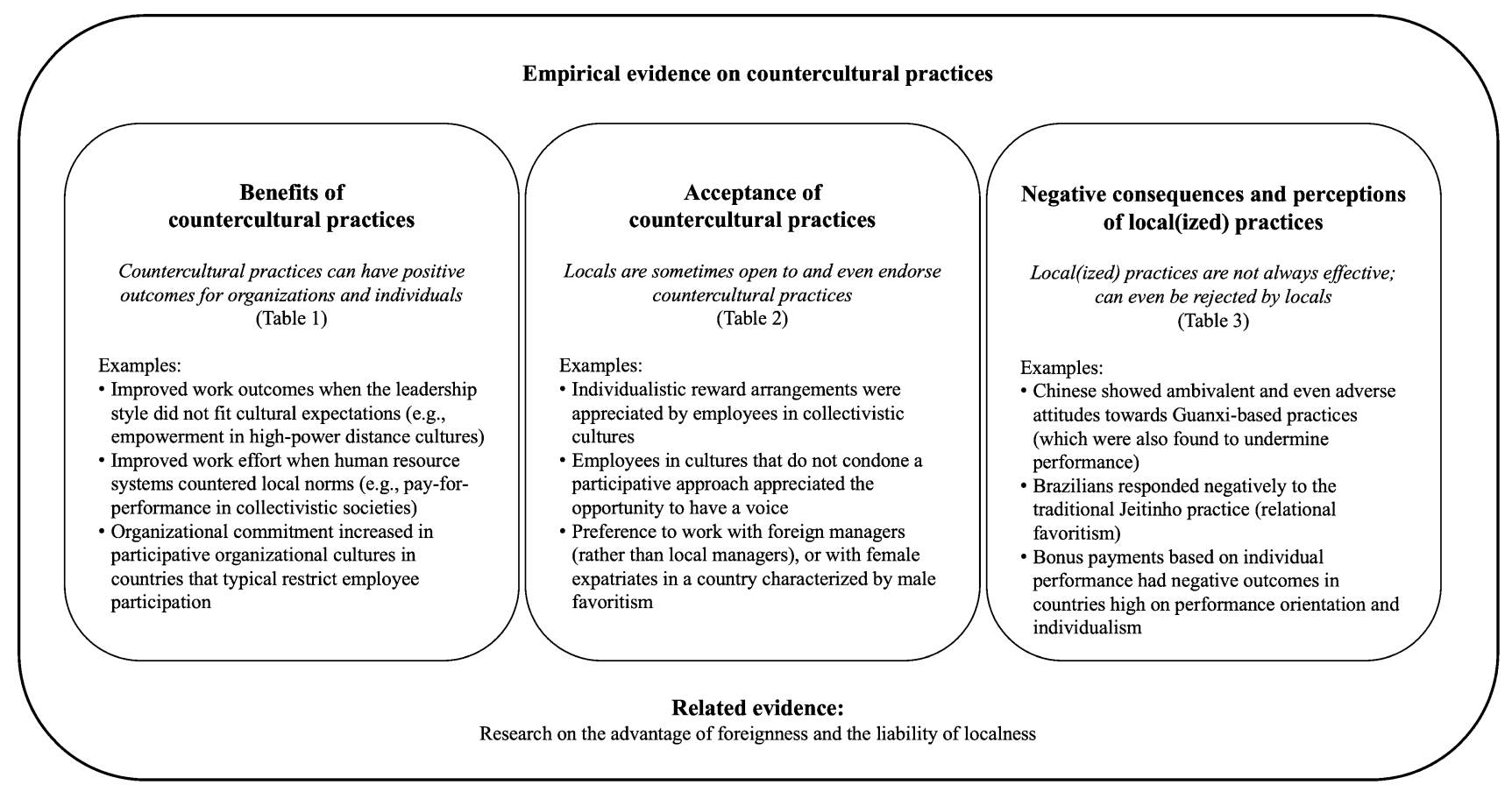

Figure 1 A summary of the empirical evidence on countercultural practices.

\section{Benefits of Countercultural Practices}

Many of the studies we identified presented some evidence that countercultural practices can be effective (i.e., have positive outcomes for organizations and/or employees). Such findings were often presented as contradicting hypotheses formulated based on existing theory (i.e., generally linking back to the dominant thesis of fit), and/or "tucked behind" more prominently discussed findings evidencing the efficacy of cultural adaptation. The 22 studies in this category are listed in Table 1, along with a summary of relevant findings from each study. Further analysis of these studies allowed us to see commonalities across them in terms of the type of management practice studied, which in turn facilitated the distillation of three broad themes: studies focused on leadership/management style and personnel; studies focused on human resource systems and practices; and studies focused on organizational culture and climate. We further discuss these themes below, and the studies associated with each of them.

Beginning with leadership/management style, we identified several studies demonstrating the efficacy of seemingly culturally incongruent leadership or management approaches. In a cross-cultural study of retail employees in China and Canada, Fock et al., (2012) found that the positive effect of empowering leadership on job satisfaction was more pronounced the higher the power distance values of the employee. Robert et al. (2000) similarly found a positive association between empowering workers and job satisfaction in the high power distance contexts of Poland and Mexico. In another study, of hotel workers in the autonomous Chinese region of Macau, the authors found that, despite the high level of power distance typically associated with Chinese culture, providing workers with autonomy and discretion in decision-making was associated with higher levels of motivation (Humborstad et al., 2008). Rao and Pearce (2016) documented similar results among those working in the high power distance Indian context: employees of managers who adopted an empowering leadership style reported better collaboration, innovation, and future team performance than employees of managers who adopted a more controlling leadership style.

We also found indications of seemingly culturally incongruent leadership/management styles having positive outcomes among individuals in the US. In an experimental study involving both US and Chinese business students, Chen et al., (2011a) found that leadership behaviors directed at the group-level (rather than any specific individual) had a stronger positive effect on psychological empowerment among the more individualistic US students (relative to the more collectivistic Chinese students). In another experimental study, Erez and Earley (1987) 
found that US students performed better on the experimental task when directed to set goals as a group instead of being individually assigned a goal.

While the results canvassed above tempt the conclusion that an empowering and/or group-oriented management style is universally effective across cultures, we also encountered evidence of the reverse effect: more control-based leadership styles having positive consequences in seemingly incongruent cultural contexts. In a study of several thousand managers (and their employees) across 50 countries, Hoffman and Shipper (2012) found that employees were more affectively committed to their organizations to the extent their manager demonstrated a control-based leadership style. This finding on its own is surprising given typical prescriptions about what constitutes "effective" leadership (at least in Western contexts), but the authors also found that this effect held irrespective of the power distance of the respondents: control-based leadership styles were positively associated with commitment even in cultural contexts low (as well as moderate and high) in power distance. Such findings obviously counter those presented earlier, but in concert, these results suggest that countercultural leadership/management approaches can produce positive outcomes under certain conditions.

Aside from studies focused directly on management style, we also identified three studies associating positive outcomes with employing foreign (rather than local) management personnel. Interestingly, all of these studies focused on Japanese managers assigned to foreign subsidiaries. Gong (2003) found that assigning Japanese leaders to foreign subsidiaries of Japanese MNEs was associated with higher labor productivity, and, surprisingly, that this effect was stronger to the extent the subsidiary's host country was culturally distant from Japan, a finding that was virtually replicated in another study of Japanese MNE subsidiaries by Gaur et al. (2007). Consistent with these findings, but focusing specifically on Japanese MNEs with subsidiaries in China, Schotter and Beamish (2011) found that employment of Japanese general managers was positively associated with subsidiary performance, although only among subsidiaries operating in regions of China where levels of foreign direct investment were already high (e.g., Shanghai, Beijing). While acknowledging the different ways these results can be interpreted (consistent with our earlier discussion of Japanese management, perhaps the Japanese personnel were adept at managing in ways consistent with the local culture, or the typical management approach of Japanese has a certain level of universal efficacy), they nevertheless suggest that foreign managers adopting foreign management approaches can, in some cases, have a beneficial impact on the organizations and employees they lead.

Beyond the issue of leadership/management style, we encountered several studies showing certain human resource systems and approaches having positive outcomes that were unexpected or surprising given the cultural context(s) under study. In the aforementioned meta-analysis of 159 studies (covering 29 countries) of the high-performance work systems (HPWS)-business performance relationship, Rabl et al. (2014) followed the standing wisdom of cultural fit in the literature and predicted that HPWS would work better in cultures of low power distance, low collectivism, and high-performance orientation. Yet, they found that HPWS had a positive impact on performance across virtually all the cultures studied, and, even more surprisingly, that this effect was stronger in countries higher in power distance and collectivism. Along similar lines, Jiang et al. (2015) found that implementing human resource practices that encouraged worker participation and transparency of information flows had a stronger positive impact on the performance of subsidiaries of a USowned MNE to the extent that the subsidiary was operating in a high (not low) power distance culture. Additionally, we found two studies reporting evidence of human resource approaches incorporating elements that would be considered typical of Western companies (e.g., ability-based rather than seniority-based promotion, pay based on individual performance) positively impacting employee attitudes in China (Gamble, 2006; Mayes et al., 2017), and an additional study reporting similar results in Bangladesh (Colakoglu et al., 2016).

While the above studies focus on the outcomes of certain forms of human resource systems writ large, we also found studies documenting positive outcomes of more specific human resource practices. By far the most common subfocus here was pay. The practice of pay-for-performance in particular has frequently been deemed inappropriate for collectivist cultures on account of the individualistic principles it embodies (e.g., Giacobbe-Miller et al., 2003; Zhu et al., 2005). Yet, several studies we encountered provide counter evidence. Chang (2006) found that South Korean workers subject to pay-for-performance reported higher levels of work effort. Moreover, when pay-for-performance was used as a part of a broader effort of developing workers, the workers 
also reported higher levels of organizational commitment. Du and Choi (2010) showed that pay-forperformance was implemented with some success in China, which would seem countercultural for a collectivist culture. They found that pay-for-performance showed a positive impact on employees' conscientiousness in China. They also observed that pay-for-performance enhances Chinese employees' affective commitment and helping behaviors when employees are pleased with the performance appraisal system in their firm. In Bloom and Michel's (2002) results, we also discovered evidence of countercultural pay practices being effective in a Western context: across 460 US companies, they found that firms with more egalitarian managerial compensation (i.e., lower levels of pay dispersion) had better rates of managerial retention, despite the US being an individualistic culture where one would generally expect egalitarianism to backfire.

Two other studies focused on specific human resource practices other than pay. The first is a mixed-methods case study of an MNE's global rollout of an employee idea suggestion initiative, a typical US approach in which employee voice is valued. In this study, Bonache (1999) found that, despite the program initially being developed and deployed in the MNE's US operations, it produced positive results (in terms of number of actionable suggestions made) when implemented unchanged in the MNE's operations in other countries, including those where the exercise of employee voice would typically be seen as incompatible with local cultural norms (e.g., Brazil, Mexico). The second study (Siegel et al., 2019) was based on a large database of companies operating in South Korea. Despite being a cultural context with entrenched gender roles that heavily favor men (particularly in terms of career prospects), the authors found that aggressively hiring and promoting women was positively associated with firms' productivity and performance.

Finally, we found two studies that spoke to the more general issue of organizational culture and climate. In the first, a study of several thousand employees of an MNE spread across 18 countries, Fisher (2014) presented evidence that a cooperative work climate helped to buffer the negative impact of role overload on organizational commitment irrespective of the level of individualism of the national culture in which the employees work. In the second study involving managers in Peru, where cultural norms generally inhibit employee participation in managerial and strategic decision-making, Parnell (2010) found that managers who viewed their organizations as more participative reported higher levels of organizational commitment than managers who viewed their organizations as less participative. It is worth noting, though, that the reverse relationship was found among the Mexican managers studied, an important reminder of our overarching thesis in this article: under certain conditions, countercultural practices can be effective.

\section{Acceptance of Countercultural Practices}

In addition to studies demonstrating the effectiveness of countercultural practices (i.e., in terms of outcomes such as firm performance, or individual motivation), we also identified 18 studies presenting evidence of openness to, and in some cases even endorsement of, countercultural practices by those subjected to them (Table 2).

One of the most frequently documented cases of locals' preference for countercultural practices is the positive attitudes shown by employees of collectivistic cultural backgrounds (e.g., Chinese, Kenyan) towards individualistic reward arrangements (Chen, 1995; Chiang, 2005; Fadil et al., 2004; He et al., 2004; Lowe et al., 2002; Nyambegera et al., 2000). For instance, Bozionelos and Wang (2007) found that Chinese workers had positive attitudes towards individual performancebased reward systems, and negative attitudes towards equality-based reward systems. This finding countered their prediction that the cultural norms of saving face ('Mianzi') and emphasis on personal relationships ('Guanxi') would lead to Chinese holding negative attitudes towards reward arrangements based on individual performance. Studies also documented the reverse pattern: individuals from individualistic cultures being receptive to more group-based pay and reward arrangements (Chen, 1995; Chiang \& Birtch, 2007, 2012; Lowe et al., 2002). Two other studies showed a preference among Japanese (Lee et al., 2011) and Hong Kong (Chaing \& Birtch, 2006) workers for pay based on individual performance rather than seniority-based pay, the latter being a conventional practice in both cultures.

We also encountered studies showing a preference for countercultural leadership/management styles. Selmer (1996), for instance, observed that Hong Kong managers rated the leadership style of managers from the US and UK as most preferable, with managers from Asia surprisingly being rated as having the least preferred leadership style. Such findings align with those of Vo and Hannif's (2013) qualitative study of Vietnamese MNE employees: 
despite the high power distance of Vietnamese culture, many employees were found to have favorable attitudes towards the more participatory, less autocratic leadership style that was typical in the US-owned MNEs that they worked for. Mellahi et al. (2010) similarly found that, in the context of the high power distance culture of India, employees responded positively to having more (not fewer) opportunities to exercise voice within their employing organizations.

We also found three studies that suggested a preference for practices that go against their own cultural norms. Varma et al. (2006) found that, despite the typical favoritism towards men in Indian culture (particularly in relation to work and professional matters), Indian employees showed a preference for working with female over male expatriates. Gong (2009) paradoxically found that consumers were more receptive to online shopping, a consumption channel typically viewed as riskier than physical shopping, in countries typically viewed as higher on the cultural dimension of uncertainty avoidance.

Taken together, the studies described above reinforce the findings reported earlier on the efficacy of countercultural practices and reiterate that they cannot simply be discounted as mere anomalies: people and groups do sometimes seem to prefer and desire work-related practices that are not necessarily aligned with, and in some cases even opposed to, the norms and values of their culture. Therefore, these studies, along with those we present in the next section, help to reveal the psychological elements of a causal chain linking countercultural practices to positive outcomes: certain countercultural practices, under certain conditions, can have real and legitimate benefits, not merely because of chance or luck but also because they are perceived favorably and consequently embraced by those subjected to them.

\section{Negative Consequences and Perceptions of Local(ized) Practices}

A third category of studies we have identified as relevant did not necessarily show the effectiveness or acceptance of countercultural practices, but revealed that culturally-congruent, normalized, or deliberately localized practices are not necessarily beneficial or perceived positively by locals. We identified 14 such studies in this category, presented in Table 3, which we elaborate below.

The most common variant of this class of studies were those focused on the Chinese practice of guanxi. Despite being a highly embedded aspect of Chinese culture, we encountered several studies in which Chinese employees held ambivalent and sometimes even adverse attitudes towards guanxi. For instance, Chen et al. (2004) found that the use of guanxi as a part of human resource management was negatively associated with Chinese employees' trust in their managers. Using a mixed-methods approach, Warren et al. (2004) also documented the complex attitudes held by Chinese workers towards guanxi, finding that the perceived benefits and downsides of guanxi vary considerably, depending on other contextual considerations (e.g., the specific nature of the relationship between the connected parties), as well as the standpoint (e.g., manager, organization, community) from which the outcomes of guanxi are evaluated. Chen et al. (2011b) distinguished between interpersonal and group level guanxi, showing that the latter can have a negative impact on employee's procedural justice perceptions. More recently, Yang et al. (2021) observed that guanxi-based HR practices may make Chinese employees emotionally exhausted, and ultimately undermine their job performance. Locals' negative responses to guanxi-like practices were also observed in other countries beyond China: Chen et al. (2017) reported that Brazilians responded negatively to the Jeitinho practice, a common form of relational favoritism in Brazil, while Boutilier (2009) presented qualitative evidence of Mexican workers holding negative attitudes towards nepotism, which they also perceived to be common in their culture.

The other studies we collected focused on a range of other aspects of local cultures, and revealed the potential downsides of such local(ized) practices and values. In Li et al.'s (2020) experimental study, for instance, it was found that Indian customers evaluated a certain marketing communication less favorably when it incorporated a highly symbolic local cultural artefact (the Ganges river). Azungah et al. (2018) presented qualitative data indicating that the locally prevalent authoritarian leadership style prevented Ghanaian employees from freely discussing their performance with managers. Peng and Tjosvold (2011) found that social face concerns were more salient for Chinese workers in interactions with Chinese as compared to Western managers, which in turn heightened the likelihood of employees acting passive aggressively towards managers. In the U.S., where individual-based performance pay is an established norm, Yanadori and 
Cui (2013) found that a high level of pay dispersion within R\&D teams was negatively related to firm innovation. Prince et al. (2020) similarly found that, contrary to their predictions, the use of bonus payments based on individual performance was associated with higher turnover and worse firm performance among firms operating in cultures with strong performance orientations and high in individualism. Finally, Goby (2015) presents a case study of the many work- and employment-related challenges encountered by workers in the United Arab Emirates arising from the normalized practice of local companies relying on foreign workers.

\section{Related Evidence: The Advantage of Foreignness and the Liability of Localness}

An emerging stream of research that provides indirect support for the countercultural practices is the literature on advantages of foreignness, and the related conversation on potential disadvantages of localness. This literature is directly relevant to our investigation, as it also challenges the fundamental field assumption of a need for cultural fit; therefore, we provide here a brief overview of studies related to these topics, indicating links between existing research in IB/IM and the phenomenon of countercultural practices.

The advantage of foreignness has been defined as "intangible social-cognitive perquisites, benefits, and privileges towards foreign organizations via-avis indigenous organizations." (Shi \& Hoskisson, 2012: 104). Studies on the advantages of foreignness challenge the traditional IB theme positing that foreignness is a source of liability. For instance, Sethi and Judge (2009) found that American automobile companies enjoyed their "foreignness" in India where local government and customers regarded foreign companies more highly than domestic companies. Un (2011) found that, other things being equal, foreign firms are more likely to achieve better innovation performance than local firms. Taussig (2017) reasoned that foreignness provides multinational companies with the advantage of not being constrained by local norms and networks. This lack of local embeddedness consequently allows foreign companies to make flexible strategic decisions. Edman (2016b) found that foreign financial institutions operating in Japan capitalized on their foreign identity, which allowed them to introduce innovative products and services into local markets. Joardar and $\mathrm{Wu}$ (2017) explored the impact of foreignness at the individual level, showing that foreignness of entrepreneurs has a curvilinear relationship with their performance, where both low and very high level of foreignness are associated with higher business performance.

The inversion of the advantage of foreignness is the recently proposed concept of liability of localness: the disadvantages associated with domestic companies that operate only in their own country. Un (2016) found that the localness of a firm undermines its innovation performance. She argued that this is driven by the low level of multiculturalism and the lack of global networks through which new ideas can be generated. Husted et al. (2016) suggested that local firms suffer from the liability of localness as local stakeholders perceive their own domestic firms to be inferior to multinational corporations in terms of product quality, manufacturing systems, and sustainability activities. Perez-Batres and Eden (2008) found that the liability of localness becomes a serious concern in the context of emerging markets where institutional arrangements are rapidly changing. They argued that domestic local firms in emerging markets are disadvantaged compared to foreign companies, because their embeddedness in the old systems of cognitive, normative, and regulatory environments makes it difficult for them to adjust into newly emerged business environments. Extending this view, Jiang and Stening (2013) argue that the liability of localness may have enduring effects even long after institutional change has occurred.

The literature on the advantages of foreignness and the liabilities of localness is consistent with our discussion on countercultural management, in the sense that it challenges the notion that going against established norms necessarily undermines the effectiveness of managers or organizations. Many studies of liability of foreignness were inspired by early versions of neo-institutional theory, which emphasized the benefit of acquiring legitimacy by conforming to three pillars (cognitive, normative, and coercive) of institutional pressure (DiMaggio \& Powell, 1983). However, institutional theory scholarship has evolved to actively embrace the value of creative deviance, as exemplified in research on institutional entrepreneurship (e.g., Greenwood \& Suddaby, 2006) and institutional work (Lawrence et al., 2011). These theoretical developments provide scholars with resources to conceptualize and legitimate the positive outcomes of going against established local norms and practices. 
Why countercultural practices might be effective and/or accepted

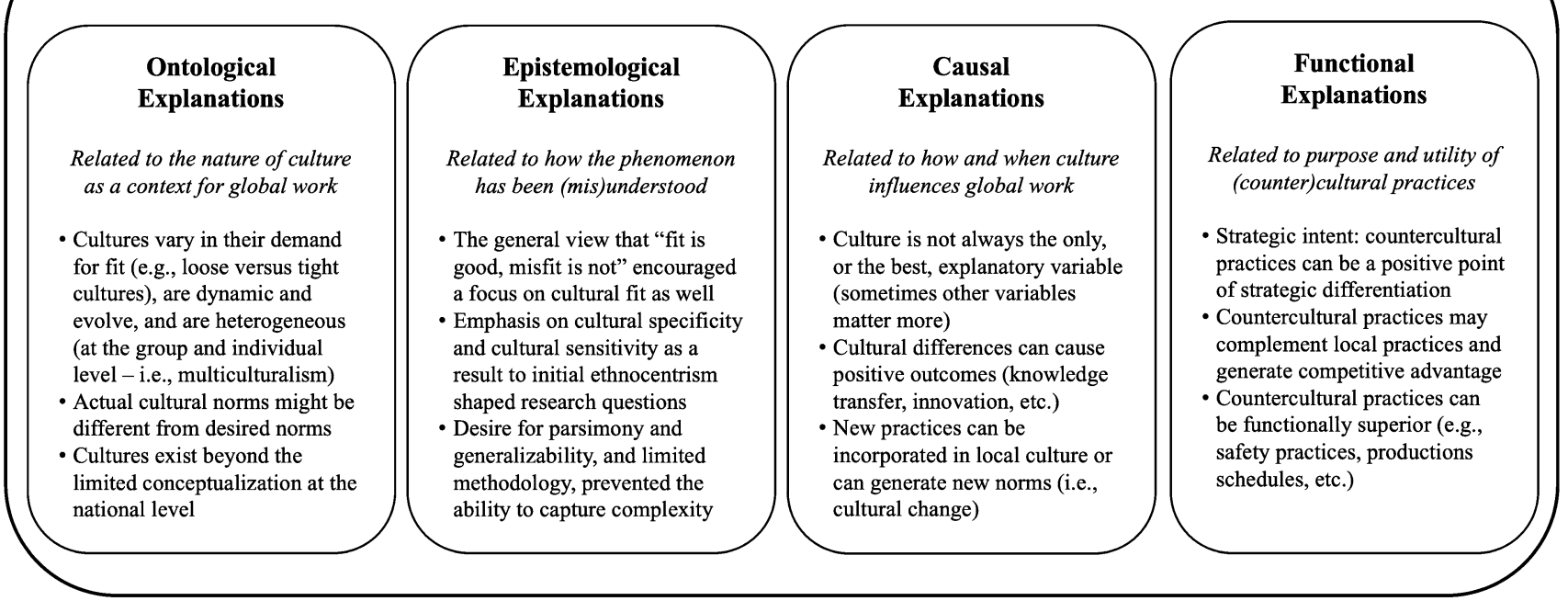

Figure 2 Potential theoretical explanations for the effectiveness and/or acceptance of countercultural practices.

\section{Making Sense of the Evidence on Countercultural Practices}

The empirical evidence of countercultural practices we have canvassed above, while supportive of our argument, is rarely accompanied by theoretical explanations purposefully aimed at explaining why and when such practices work. As discussed earlier, the predominant focus on hypothesizing the need for cultural fit and adaptation renders such findings puzzling, inconclusive, and even problematic. As such, the typical explanations offered relate to study limitations, the peculiarity of the research context, and anomalies and outliers. We contend that, by adopting a lens of understanding that allows such findings to be significant, relevant, and legitimate, a variety of explanations can be offered. We have organized these explanations into four categories, each prompting, as we will show later, interesting avenues for future research in global work. These categories are: (1) ontological explanations (i.e., explanations that reside in the nature of the context of global work); (2) epistemological explanations (i.e., explanations related to the way the phenomenon has been understood, or rather, misunderstood); (3) causal explanations (exploring conditions and circumstances that lead to effectiveness of countercultural practices, along with explaining how such effects occur); and (4) functional explanations (referring to the potential purpose and utility of countercultural practices). We detail these categories below, along with providing a summary in Figure 2.

\section{Ontological Explanations}

Clearly, the investigation into why countercultural practices might be effective must begin with exploring the context of global work, and, in particular, the main protagonist in this story: culture. It is important to note that, in the context of research related to the relevance of culture to IB/ $\mathrm{IM}$, the focus is largely on the home-country culture, with limited understanding and consideration of local cultural features. Most models of local adaptation consider the host-country culture in terms of its "distance" from the home culture (Shenkar, 2001). As noted above, theory (and the practice that followed it) often depicts the host culture as homogeneous, well-defined, and consistent (Tung, 2008). Several major theoretical advancements in the study of culture demonstrate that such a view is inaccurate (e.g., Caprar et al., 2015), and offer explanations with regard to why countercultural approaches might sometimes be appropriate. The first development we bring to attention is the concept of tightness-looseness of cultures, associated with cultural change. The second important development is the distinction between desired cultural values and actual practices. Finally, the way culture is conceptualized in general is also relevant to our discussion. These well-documented culture-related phenomena have direct implications for understanding why countercultural practices are sometimes effective. 
Cultural strength, cultural change, and acculturation The concept of tightness-looseness has been long discussed in the study of culture as the strength of social norms and the degree of sanctioning within societies (e.g., Berry, 1967; Pelto, 1968; Triandis, 1989), yet its application is largely missing in the study of global work. The concept was brought back to attention by Gelfand et al. (2006), who proposed that the tightness-looseness dimension has implications both at the individual and organizational levels, influencing the amount of intra-cultural variance, and, implicitly, the variability across organizations. In terms of adapting business practices to local cultures, it is fair to expect that not only cultural distance but also the tightness-looseness of the host culture is important: a loose culture means norms are less clearly defined, and therefore difficult to identify, and when they can be identified, the level of "compliance" to such norms is limited, allowing for greater variability in terms of what is accepted and/or expected. Thus, in loose host cultures, the concern for cultural fit is less important.

Finally, cultures - especially loose ones - are likely to be experiencing a process of change. A range of factors has led to the development of a global culture that progressively impacts all corners of the world (Arnould, 2011; Ritzer, 2018). And this change can be manifested both at the societal and individual level, with many individuals becoming multicultural because of global mobility and globalization in general. That is, individuals can internalize more than one culture (Brannen \& Thomas, 2010); as a result, different cultures can coexist both at the societal and individual level, and influence perspectives and preferences in multiple ways (Lücke et al., 2014; Maddux et al., 2021). Defining cultural sensitivity against traditional values measured at the country level that may, or may not, be reflected in the employees' cultural profile defies its very purpose: modernized members of the culture might welcome non-local approaches (e.g., Caprar, 2011), and, indeed, perceive the use of localized (i.e., traditional) practices as outdated or unhelpful. All cultures are exposed to changing factors, but loose cultures are more likely to incorporate practices that are considered legitimate and/or efficient based on other external criteria, such as legitimacy or efficiency, as established in other cultures or at a global level. On the contrary, in tight cultures, the traditional model of localization may still be valid, as these cultures have clear norms that are highly sanctioned, thus inhibiting the degree to which such cultures welcome culturally unusual practices.

\section{Desired cultural values and actual practices}

As with any social construct, our understanding of what culture means is constantly evolving. Recently, several conceptualizations have helped to enhance our understanding of culture and its various features. In management studies, Hofstede's (2001) notion of the cultural onion (placing values at the core of culture, and practices as a manifestation of values) gained a lot of popularity and generated extensive research focused on identifying major dimensions describing a culture. This assumption of a perfect relationship between cultural values and practices was challenged by the GLOBE study (House et al., 2004), where values and practices were measured separately, based on the observation that "what is" in any given culture does not necessarily match "what should be". In fact, even Hofstede and his collaborators mentioned such a distinction in their study, given the fact that value items and practice items loaded on different factors, a distinction they recognized to be "present not only in the conception of the researchers, but also in the minds of the respondents" (1990: 295). While there is still debate regarding the advantages and disadvantages of the different approaches to measuring culture based on the above conceptualizations (e.g., Hofstede, 2006; Javidan et al., 2006; Smith, 2006), the data revealed by the GLOBE study indicate that there is a gap between "is now" societal culture scores and "should be" scores on certain dimensions. For instance, a study of leadership prototypes in the Middle East and North Africa using the GLOBE dimensions revealed that different values were reflected in the practice of leadership, and the preference for leadership in these countries (Kabasakal et al., 2012). Such findings also reflect the identity-related notion that people not only form perceptions of who they are at present but also ideal possible selves that detail who they wish to become in the future (Markus \& Nurius, 1986). This dualistic perspective of culture might explain why certain cultures are more open than others to taking on new business practice that appears to be countercultural (when considered against the "is now" measures): if the complexity of 
culture is properly considered, such countercultural practices might in fact be consistent with the desired aspect of a given culture, and therefore welcomed by its members.

\section{Beyond equating culture with nation}

It is widely accepted that distinct cultures can emerge at virtually any level of human organization, from nations down to families and intimate friend groups. Closely related to the significant evolution on conceptualizing culture in IB/IM, beyond defining it using national borders (e.g., $\mathrm{Au}$ 1999; Caprar et al., 2015; Taras et al., 2016; Tung, 2008; Tung \& Stahl, 2018), it may be the case that certain practices that seem "countercultural" at a national level are, in fact, culturally congruent at subnational or cross-national levels (e.g., in terms of the culture of certain regions, communities, or organizations). For instance, researchers have begun to acknowledge the unique characteristics of global cities, defined as cosmopolitan environments (e.g., Goerzen et al., 2013), and have called for moving away from traditional mean-based measures of cultural distance towards an approach which accounts for within-country cultural variation (e.g., Beugelsdijk et al., 2015). Yet, most of the studies we identified through our review focused on national culture and did not consider or control for potential "glocal" cultural effects (see Gould \& Grein, 2009), intra-country ethno-linguistic fractionalization (see Luiz, 2015), or the existence of transnational and subnational archetypes (Venaik \& Midgley, 2015).

The focus on national culture in research studies would be less problematic if such studies employed samples that were truly representative of a country's population (and thus its culture), but the inherent limitations of scholarly research (e.g., gaining access to data, resource constraints) mean that population-level samples are rarely the case. Rather, researchers usually make use of samples of firms or individuals from specific geographic areas, occupations, industries, organizations, and communities, all of which constitute subnational collectives that can have subcultures that differ from the culture of the country "as a whole". Moreover, measurements and methodology that do not consider the large variability in cultural values and practices (deviation from the mean) within the population studied (Beugelsdijk et al., 2015), and a restricted range of methodologies (Nielsen et al., 2020), further limit the accuracy of understanding the relationship between business practices stemming from a home culture and the host/local culture. The MNE subsidiaries can themselves represent subcultures that challenge traditional geographical perspective on defining cultures (e.g., Caprar, 2011; Goerzen et al., 2013). In this way, practices that are in fact a good fit with a particular (sub)culture are incorrectly cast as "countercultural", a label rendered by researchers' overly blunt assumptions about the default culture of their study's participants, rather than any mismatch between the culture and the practice in question.

\section{Epistemological Explanations}

The historical account on the development of the cultural fit thesis offered earlier suggests that it was not its unquestionable validity that made it so central to IB/IM. Rather, the exaggerated focus on cultural fit seems to be better described as a typical case of "more of the same" principle of problem formation (Watzlawick et al., 1974). In the initial stages of globalization, the typical approach was, indeed, culturally insensitive (as noted in our review): the companies may have been ignorant regarding the existence of significant cultural differences, or, if they recognized such differences, probably did not recognize their relevance to business. Furthermore, historical, political, and economic reasons might have supported an ethnocentric view on the part of Western companies, and on the part of Western academics. Such views clearly expressed at the time, as we saw in our review - needed correction, and, naturally, the culturalist (or the culture-specificity) view developed. However, if the extreme of convergence (or culture-free approach to business) was biased, so was the corrective action of "fit", especially when "fit" became a "more of the same" principle (an exaggerated emphasis on what has been ignored before), leading to ignorance of other aspects (i.e., "contexts", as mentioned in some of the articles reviewed). In other words, the same exclusivity in focus that caused the initial problem also plagued the proposed solution. The obsession with demonstrating the importance of cultural fit (also fueled by an ideological stance expressed in the morality of cultural sensitivity) precluded some researchers from acknowledging that cultural fit is not always helpful.

In addition, due to a quest for parsimony and generalizability (Poole \& Van de Ven, 1989), academic theories tend to oversimplify realities characterized by complexity and variation (Glynn et al., 2000). In tracing the development of the cultural fit 
thesis, we note that the debate between localization and standardization stems from a dichotomous logic, in which alternatives are seen as mutually exclusive (i.e., it is either standardization or localization, not both). However, as suggested by Ralston et al.'s (1993) findings, such absolutist views do not accurately describe the reality: evidence for both convergence and divergence has been found, prompting the development of the newly coined concept, "crossvergence". It is still rather difficult to explain why this concept has not influenced thinking in the field to a greater extent; for instance, the Pudelko and Harzing (2007) study did not even mention it in their otherwise very meticulous review of the convergence/divergence debate. Perhaps one of the reasons is the complexity of the concept and the need to further explain its meaning (Witt, 2008). It is also possible that limitations emphasized by Tung (2008), who drew attention to the fallacious assumptions of cultural homogeneity and cultural stability over time (problems specific to most cross-cultural studies, in fact), also limited the theoretical appeal and applicability of the concept. In other words, there were conjectural factors that facilitated the development of a unilateral view (that of cultural fit), while hindering the recognition of possible and valuable alternative solutions. As Lewis (2000) noted - based on initial ideas formulated by Cameron and Quinn (1988) - there is a need for new perspectives in addressing the complex problems specific to the field, especially recognition of the paradoxical nature of certain phenomena. The topic explored here would undoubtedly benefit greatly from such new perspectives.

Related to the above, we also note that the studies uncovered by our review are methodologically diverse. While it might be tempting to single out inductive, qualitative approaches as better suited to uncovering the nuanced or counterintuitive properties of phenomena such as culture (e.g., Morgan \& Smircich, 1980), the evidence we have presented as to the efficacy of countercultural management is also comprised of a large contingent of deductive, quantitative studies. This observation is important, because it emphasizes that the tools used to study culture and cultural differences are arguably less important than the mindset and assumptions of the researcher who is using them. As noted earlier, many of the articles containing evidence of the efficacy of countercultural practices do not foreground these findings. On the contrary, the authors often reported being puzzled or confused by them. We contend that, with a different, more delicate set of assumptions about culture and IB/IM writ large, and largely irrespective of the specific tools used to investigate these things, such findings would not be seen as anomalous or incoherent, but rather a natural state of affairs.

\section{Causal Explanations}

The explanations above have themselves an underlying assumption that needs to be questioned: that is, the fundamental assumption that culture is relevant as a causal variable to managing global work. The extent to which this assumption is fundamental might be reflected in the likely reaction most readers would have when reading these lines; especially for those preoccupied with the study of culture in business, it is almost unthinkable to question whether culture matters. Yet, culture might not always be an explanatory variable. Researchers have long cautioned against indiscriminately using culture as the default "go to" cause for all questions related to managing globally (e.g., Ajiferuke \& Boddewyn, 1970), a message recently renewed in a recent collection of experts' reflections on the past, present, and future of cross-cultural management education. Several of these experts refer to the fact that "there may be a temptation to overemphasize culture to the detriment of management", that "culture is never the 'only' explanation for what's gone wrong in a particular situation, and often it's not even the 'biggest' explanation", and that what we should aim for is "understanding how and when culture matters and not overemphasizing cultural explanations" (Szkudlarek et al., 2013: 478-480).

Empirical studies also suggest that businesses do not necessarily suffer from increasing cultural heterogeneity (e.g., Gomez-Meija \& Palich, 1997), and that the traditionally identified cultural differences are diminishing (e.g., Gerhart \& Fang, 2005). Similarly, studies on international human resource management (e.g., Von Glinow et al., 2002) identify some regional- and country-specific practices, but also universals, suggesting the need for a shift in how we think about such research (i.e., the need to consider multiple contextual elements). Finally, a meta-analytic review of Hofstede's cultural value dimensions (Taras et al., 2010) revealed that, while cultural dimensions predict a range of organizational outcomes, some of these other variables (such as personality traits and demographics) were even stronger predictors. As such, a first causal explanation for findings that disconfirm the 
cultural adaptation imperative might be that variables other than culture are more important antecedents for explaining the effectiveness of certain business practices.

Of course, culture is often a relevant variable, and its effect can be the one typically portrayed in the literature (i.e., an effect that urges cultural fit). Yet, at present, there is something of a default one-sided view that management practices that fit local cultures are desirable, and a more balanced view is needed (Stahl \& Tung, 2015): cultural differences, and the misfit generated by such differences can be beneficial. It is this type of causality that the recent positive organizational scholarship perspective has invited researchers to consider (Stahl et al., 2016). Theorizing about how cultural differences produce positive effects is still emerging, but studies have already suggested that cultural differences facilitate knowledge transfer (e.g., Sarala \& Vaara, 2010; Vaara et al., 2012), stimulate innovation and exploration (e.g., Morosini et al., 1998), and increase learning (e.g., Nachum et al., 2008). More specifically, countercultural practices may carry with them knowledge developed over time and in a variety of settings (and not necessarily specific to or useful only in the home country) and may trigger alternative perspectives and new solutions because they shake the status quo. As such, by adopting countercultural practices, MNEs may introduce contradictions between ways of doing business within a subsidiary, which would instigate dialectic organizational change processes (Ford \& Ford, 1995: Van de Ven \& Poole, 1995) that ultimately result in better adaptation to the complexity of a globalized world.

Finally, a causal explanation might be the fact that, although the misfit generated by countercultural practices could be associated with certain negative consequences, these might be mitigated to the extent that certain functional benefits (detailed below) prevail. In a study about the integration of practices that are a poor fit to the organizational culture, Bertels et al. (2016) discovered several strategies used by employees to address the consequences of adopting new, countercultural routines. Such strategies are consistent with perspectives proposed by practice-based theories (e.g., Feldman, 2003), where new practices can lead to a redefinition of existing cultural norms. In other words, new routines and practices are incorporated into the culture of the organization, which evolves and changes to align itself with these new practices (e.g., Canato et al., 2013). Of course, this causality mechanism eventually leads to fit, but a fit achieved by adapting the culture, rather than the practice. Luo (2016) defined this process as reverse adaptation: local employees adopt new values and norms, becoming what Caprar (2011) identified as "foreign locals", i.e., local employees who might be more aligned culturally with the "foreign" culture of their employing organization than that of their own country.

\section{Functional Explanations}

While causal explanations get to the core of why and how countercultural practices might work, functional explanations can provide additional understanding, beyond specific causal relationships (Enc \& Adams, 1992). In this context, a functional explanation would be any possible strategic reason for an MNE to actively select a countercultural practice, even when it was not required based on local laws.

Countercultural practices can be a method of strategic differentiation. Strategy researchers have recognized the benefits of being distinctive; indeed, differentiation is one of the most critical strategies for competitive advantage (Porter, 1985). Such differentiation is typically discussed in terms of products or services, but differentiation in terms of business practices can be beneficial in terms of employing approaches that are not only unique but also difficult to imitate. This argument is also made in the resource-based view (Barney, 1991) as a source of competitive advantage, and has been alluded to as a potential explanation for the adoption of high-performance work systems, in spite of their seeming incongruence with local contexts (e.g., Rabl et al., 2014). For instance, in a case study of Disney's international resort operations, Brannen (2004) suggested that the foreignness of American culture was a critical asset for the Japanese subsidiary of Disney: its mission is to sell a unique experience, which is expected to be aligned with a foreign culture. As such, foreignness in such a context represents an advantage rather than a disadvantage.

Along with distinctiveness, another factor with a positive impact on performance, also developed in the strategy literature, is complementarity. While cultural fit has been described as an antecedent of merger and acquisition success (e.g., Chatterjee et al., 1992), strategic complementarity is also often mentioned as having a positive impact (Bauer \& Matzler, 2014; Collings et al., 2018). While such complementarity refers to the similarity between 
the strategies of the two merging organizations, the concept can extend to the nature of business practices in general. The use of countercultural practices that complement local practices, as opposed to aiming to localize all business practices, can provide an organization with a wider range of options and new opportunities that would otherwise be difficult to create.

\section{Towards a Research Agenda on Countercultural Practices}

The explanations we offered for the evidence supporting the use of countercultural practices, while a helpful starting point, are far from fully capturing the why and when of countercultural practices. In particular, the question of when countercultural practices are effective, or should be used as a conscious choice (as opposed to being a default option), might be the most accessible point of departure in designing studies with potential for contributing to both theory and practice. Our objective here is to lay the foundation for a research agenda that sets as the focal point of interest the study of countercultural practices as one legitimate approach to conducting international business.

\section{Key Theoretical Premises}

A first important point ensuing from our review of the existing evidence and the preliminary theoretical insights we formulated is that the phenomenon of countercultural practices is not necessarily incompatible with existing theoretical knowledge. Although the notion of countercultural practices challenges a dominant perspective in the field, its feasibility as a topic of study resides in the fact that it reflects an interesting empirical phenomenon, while at the same resonating with recent theoretical developments, such as the conversations around the need to rethink cultural distance and foreignness in IB/IM (e.g., Edman, 2016a; Stahl et al., 2016; Taussig, 2017).

The essential and obvious proposition of a future research agenda is that in certain circumstances, businesses might benefit from the use of countercultural practices, that is, approaches that are different from those based on local norms, commonly used in the host culture, and formulated based on the typical characterizations of the host culture. A systematic exploration of what exactly such circumstances are is therefore much needed. The literature we reviewed suggests that these circumstances might relate to the following key themes: strategic intent, local preferences, institutional drivers, and social responsibility.

\section{Strategic intent}

The possibility of choosing to behave in a way that is inconsistent with host cultural norms has been highlighted through the concept of cultural agility, developed to better understand the necessary cultural responses of global professionals (Caligiuri, 2012, 2021). Cultural agility enables professionals to, as needed, toggle across three cultural responses by (1) adapting to local cultural norms when needed (often used by global professionals working in sales and marketing), (2) minimizing the effect of culture to hold a company standard when needed (often used by professionals working in production and quality assurance), and (3) integrating diverse norms when needed (often used by those working in innovation or global teams). All three are acceptable cultural responses contingent on the demands of the situation. Each cultural response - whether adaptation, minimization, or integration - has its own set of behaviors, and global professionals with the ability to use each approach have higher ratings of global professional success (Caligiuri \& Tarique, 2016). This cultural agility approach suggests that the fit or intentional misfit with culture depends on the demands of the context with respect to the desired strategic outcome. Of course, the strategic intent must consider what is suitable, not only from the perspective of the organization but also from the perspective of other stakeholders (including the locals). Indeed, it seems that most studies focusing on countercultural practices primarily consider individual-level variables, as opposed to firm-level variables, so future research could further explore the impact of such practices at different levels, with the possibility of incongruence or synergies between practices adopted for business reasons and practices driven by local stakeholders.

\section{Local preferences}

Beyond addressing the question of when countercultural practices might be strategically appropriate, another broader, more complex, but important direction of research suggested by our analysis is exploring what it means to adapt, and what should be the reference point for adaptation (i.e., adapting to what?). If previous common knowledge was to "do as Romans do", expanding and updating this knowledge requires answers to questions like "what would Romans prefer you to do", what would fit 
with their goals (which may not be necessarily what they are doing now), or perhaps even questioning if "Romans" want to, or should do, what they are currently doing. Of course, the answer is not to be provided by the "visitor", but rather by an understanding of what it means to adapt, respect, or contribute to the local culture. As such, future research in this category could take as its core aim a focus on truly understanding locals' expectations in terms of business or management practices, how they respond to different approaches, and, as such, formulating more useful models explaining the effectiveness of different practices across cultures.

Following on from the theoretical developments noted above, it seems reasonable to argue that practices that are consistent with aspirations of local employees will be readily embraced, despite their appearance as "countercultural", and their proven efficiency in other cultures might also be manifested in these new cultures. Consequently, we suggest that future research should explore the hypothesis that, in cultures where there is a gap between actual practices and desired values, a practice that is countercultural but consistent with such desired values would be quickly legitimated, easily embraced, and potentially more effective than approaches that are consistent with current local practices. For instance, a culture high in power distance might manifest "should be" or "desired" values of lower power distance. Companies proposing employee relationships with management based on lower power distance principles might be welcomed in these cultures, and in general practices consistent with lower power distance (e.g., involving employees in organizational decision-making), would not disregard, but better fulfill, the local employee's needs.

It might also be the case that business practices that align with universal human motivators would have the greatest level of acceptance, regardless of local culture. Applying self-determination theory to the broad-based acceptance of counterculture business practices, we need to recognize that the behaviors influenced by those practices are motivated to fulfill three basic and universal psychological needs: autonomy, competence, and relatedness (Deci \& Ryan, 2000, 2002; Deci et al., 2017; Ryan \& Deci, 2000). With greater autonomy, employees have more freedom and control to ensure personal alignment between their values and their behaviors. Relatedness represents employees' basic desire to connect in meaningful ways with others. Employees' need for competence reflects their desire to address challenges without being anxious (when the demands are too high for their level of competence) or bored (when demands are too low for their level of competence). With respect to countercultural business practices, self-determination theory suggests that the more employees can satisfy their needs through the practice, the more they will engage in them (Deci et al., 2017), and achieve higher levels of job satisfaction (Graves \& Luciano, 2013), organizational commitment (Rasskazova et al., 2016), and job performance (Baard et al., 2004). Further exploring these potential links could generate new research and insights relevant to managing a global workforce.

Institutional drivers. Countercultural practices may also be understood and further studied from the perspective of institutional theory. From this perspective, organizations tend to fit their environment for reasons of legitimacy (DiMaggio \& Powell, 1983), and the traditional view on adaptation, as we have shown, is certainly consistent with such a tenet of isomorphism. However, in the traditional view of localization of practices, such legitimacy has been judged against general descriptions of cultures or institutions linked to national contexts, without consideration for multiple institutional drivers and logics. As noted by Kostova et al. (2008), the organizational fields against which legitimation is to be assessed in the case of MNEs are rather difficult to define, or are at best fragmented, multiple and, in many cases, conflicting (Schneiberg, 2007). We are proposing a more careful consideration of the "legitimating" process: if local adaptation is meant to address sensitivity to local cultures, or compliance with institutional forces, the focus should be on properly understanding the institutional contexts. The potential overlap between culture and institutions has often been discussed (e.g., Beugelsdijk et al., 2017; Hatch \& Zilber, 2012; Kraatz et al., 2020; Patterson, 2014), but studies integrating both informal and formal drivers of conformance and change (e.g., Caprar \& Neville, 2012), along with consideration for power dynamics (Geary \& Aguzzoli, 2016), could be fruitful in understanding not only adoption and non-adoption of certain practices but also why when non-isomorphic practices are effective.

Social responsibility. There are also opportunities here for deepening understanding of the ethics and social responsibility of business. These considerations are particularly important given recent questioning of the role and value of globalization, reignited attachment to local cultures, and, at the 
same time, the need for globally coordinated efforts to deal with grand global challenges (George et al., 2016). The idea of countercultural practices will certainly raise concerns about a potential return to, and legitimation of, cultural imperialism. However, by formulating a research agenda around the questions suggested above, the shift is one that involves considering the needs, desires, and objectives of the local employees, and, ultimately, of the local society, as defined by themselves, not as defined by outdated cultural studies and/or stereotypic cultural profiles. Practices guided by outdated cultural stereotypes that fail to account for cultural change, acculturation, intranational diversity, and evolving local aspirations and capabilities are clearly not the way to practice true cultural sensitivity.

These directions of research would be consistent with the aforementioned notion of intracultural variability (Tung, 2008), further complicated by the presence of competing logics (Friedland \& Alford, 1991), represented in our case by the distinction between culture "as is" and culture "as it should be". Besides the incompleteness associated with consideration of culture "as is" as the only logic or legitimating reference, the "should be" aspect of culture might represent a better legitimating standard, especially in cultures where current ("old") practices are being deinstitutionalized and new practices are being legitimated by their symbolism as "modern", "updated", or simply due to being consistent with where the society is going (or wants to go). Many developing cultures hold such views with regard to certain Western practices, and in these instances localization by congruence with local norms is more likely to gain rejection, rather than legitimation, with direct negative effects on both the adoption and the efficiency of such practices.

In other words, we suggest a repositioning of the discussion around standardization versus localization by adopting conceptualizations of culture that allow for recognition of its complex nature, especially in the current globalized context. Examples include the ambiguity paradigm (Martin, 2002), which proposes a more fragmented, individualized view on culture; the situated dynamic framework (Leung \& Morris, 2015), delineating important distinction between different aspects of culture (i.e., values, schemas, and norms) and the role they play in IB/IM; the Glocalized Community Culture Model proposed by Gould and Grein (2009), in which culture is situated and produced within dynamic communities of practice; and the friction, contact-based framework (Shenkar et al., in press) in addressing dynamics of cross-cultural interactions. Each of these approaches suggests a far more nuanced view of the role of culture, a view which would offer a better understanding of the relationship between the most appropriate business practices for a given context.

Acknowledging and understanding the phenomenon of countercultural practices brings a more balanced and sophisticated view on the role of culture in IB, refocusing attention on generative aspects of challenges associated with globalization and the potential for increased knowledge transfer (Sarala \& Vaara, 2010) that leads to co-evolution and learning (Luo, 2020), as opposed to taking the usual predominantly negative view of differences, diversity, and cultural distance (Stahl \& Tung, 2015). As we have shown in this review, countercultural practices are an inevitable (and not necessarily deleterious) reality, and a phenomenon that could generate both new answers to old questions, and new questions about old phenomena. A research agenda that allows for more nuance in how we approach cultural interactions (Adler \& Aycan, 2020), including the need to go beyond broad templates and normative assumptions, and instead determining what is appropriate in each situation, will further enhance our capacity to inform practices and policies meant to address both local and global challenges.

\section{Potential Practical Implications of a Research Agenda on Countercultural Practices}

Promoting a research agenda centered on the cultural adaptation imperative has, in the past, facilitated a myriad of recommendations that were, through a more nuanced lens, oversimplified. Encouraging firms to adapt local practices did not capture the many reasons to intentionally engage in countercultural practices, such as strategic intent, local preferences, institutional drivers, and social responsibility. Insights gained by addressing our questions formulated above will most likely not produce simple, well-defined recipes for those conducting business across borders. However, they are likely to encourage business leaders to engage in more sophisticated deliberations over the selection of practices. These deliberations will include the need for a far deeper understanding of the way in which various practices interact with societal expectations, strategic goals, employees' preferences, and the like. In fact, such careful 
deliberation was prescribed decades ago for working even within national boundaries (e.g., Dansereau et al., 1995); it is certainly relevant when working across multiple cultures. It is important, however, to determine when and how culture should drive the choice of business practices, or the adjustment of such practices across different contexts. Such a perspective does not exclude adaptation, when adaptation makes sense from the perspective of the intended objectives and that of stakeholders involved (which includes local employees and communities). However, it does not prescribe adaptation by default, as it leaves room for a genuine exploration of what is needed. Systematic exploration of this topic will be beneficial to business leaders and managers who need to make choices based on a deep understanding of multiple contextual variables that, hopefully, we, as academics, can provide, once we free ourselves from the constraints of our own limiting assumptions.

To conduct research on the effectiveness of countercultural practices, we recommend both a multidisciplinary approach and a multilevel research design, to allow for more nuanced interpretations. Consider the countercultural findings described in this paper which indicated that collectivist cultures demonstrate a preference for individualist compensation systems (e.g., pay-forperformance). In this interpretation, the organizational level IB perspective might interpret the findings as an anomaly in the corporate culture, whereas the individual-level psychology perspective might interpret the finding as fulfillment of the universal need for autonomy and competence. Research teams representing different academic disciplines and research designs capturing multiple levels would be warranted to capture the role and effectiveness of countercultural practices.

\section{CONCLUSIONS}

Countercultural business practices represent a reality of international business that calls for, and indeed deserves, attention. The absence of countercultural practices as a focal topic in IB/IM research can be excused by a legitimate focus on cultural adaptation in the context of a field predominantly preoccupied with achieving fit and consistency. However, the fact that countercultural approaches can never be fully avoided when working across multiple cultural contexts, and the fact that the substantial evidence reviewed here suggests such approaches can be valuable, brings to the fore the necessity and opportunity to build a complementary research agenda on countercultural practices. Such a research agenda has the potential to progress scholars and practitioners towards the goal of fully understanding how best to account for culture in the study and practice of international business.

\section{OPEN ACCESS}

This article is licensed under a Creative Commons Attribution 4.0 International License, which permits use, sharing, adaptation, distribution and reproduction in any medium or format, as long as you give appropriate credit to the original author(s) and the source, provide a link to the Creative Commons licence, and indicate if changes were made. The images or other third party material in this article are included in the article's Creative Commons licence, unless indicated otherwise in a credit line to the material. If material is not included in the article's Creative Commons licence and your intended use is not permitted by statutory regulation or exceeds the permitted use, you will need to obtain permission directly from the copyright holder. To view a copy of this licence, visit http://creativecommons.org/licenses/ by/4.0/.

\section{NOTES}

${ }^{1}$ In mid-2021, Newman and Nollen (1996) has been cited 349 times in the Social Sciences Citation Index and 235 times in Business Source Ultimate Database, while Dunphy (1987) has been cited 32 times and 25 times, respectively; and Ouchi \& Jaeger (1978), not included in the Social Sciences Citation Index, has been cited just 31 times in the Business Source Ultimate Database. 


\section{REFERENCES}

Abegglen, J. C. 1973. Management and worker: the Japanese solution. Tokyo: Kodansha International.

Adler, J. N., \& Aycan, Z. 2020. Setting the stage: cross-cultural interactions - creating success in the twenty-first century. In B. Szkudlarek, L. Romani, D. Caprar, \& J. Osland (Eds.), The SAGE handbook of contemporary cross-cultural management. Thousand Oaks: Sage.

Aguilera, R. V., Marano, V., \& Haxhi, I. 2019. International corporate governance: a review and opportunities for future research. Journal of International Business Studies, 50(4): 457-498.

Aguzzoli, R., \& Geary, J. 2014. An "emerging challenge": the employment practices of a Brazilian multinational company in Canada. Human Relations, 67(5): 587-609.

Ajiferuke, M., \& Boddewyn, J. 1970. "Culture" and other explanatory variables in comparative management studies. Academy of Management Journal, 13(2): 153-163.

Alvesson, M., \& Sandberg, J. 2011. Generating research questions through problematization. Academy of Management Review, 36(2): 247-271.

Arnould, E. J. 2011. Society, culture, and global consumer culture. In J. Sheth, \& N. Maholtra (Eds.), International encyclopedia of international marketing. New York: WileyBlackwell.

Au, K. 1999. Intra-cultural variation: evidence and implications for international business. Journal of International Business Studies, 30(4): 799-812.

Aycan, Z., Kanungo, R. N., Mendonca, M., Yu, K., Deller, J., Stahl, G., \& Kurshid, A. 2000. Impact of culture on human resource management practices: a 10-country comparison. Applied Psychology: an International Review, 49(1): 192-221.

Azungah, T., Michailova, S., \& Hutchings, K. 2018. Embracing localization: evidence from Western MNEs in Ghana. Cross Cultural \& Strategic Management, 25(4): 690-715.

Baard, P., Deci, E., \& Ryan, R. 2004. Intrinsic need satisfaction: A motivational basis of performance and well-being in two work settings. Journal of Applied Social Psychology, 34(10): 2045-2068.

Barney, J. 1991. Firm resources and sustained competitive advantage. Journal of Management, 17(1): 99-120.

Bartlett, C. A., \& Ghoshal, S. 1989. Managing across borders: the transnational solution. Boston: Harvard Business School Press.

Bauer, F., \& Matzler, K. 2014. Antecedents of M\&A success: the role of strategic complementarity, cultural fit, and degree and speed of integration. Strategic Management Journal, 35(2): 269-291.

Berry, J. W. 1967. Independence and conformity in subsistencelevel societies. Journal of Personality and Social Pscyhology, 7(4): 415-418.

Bertels, S., Howard-Grenville, J., \& Pek, S. 2016. Cultural molding, shielding, and shoring at Oilco: the role of culture in the integration of routines. Organization Science, 27(3): 573-593.

Beugelsdijk, S., Maseland, R., Onrust, M., van Hoorn, A., \& Slangen, A. 2015. Cultural distance in international business and management: from mean-based to variance-based measures. The International Journal of Human Resource Management, 26: 165-191.

Beugelsdijk, S., Kostova, T., \& Roth, K. 2017. An overview of Hofstede-inspired country-level culture research in international business since 2006. Journal of International Business Studies, 48(1): 30-47.

Bloom, M., \& Michel, J. G. 2002. The relationships among organizational context, pay dispersion, and managerial turnover. Academy of Management Journal, 45(1): 33-42.
Bonache, J. 1999. The international transfer of an idea suggestion system. International Studies of Management \& Organization, 29(4): 24-44.

Boutilier, R. 2009. Globalization and the careers of Mexican knowledge workers: an exploratory study of employer and worker adaptations. Journal of Business Ethics, 88(S2): 319-333.

Bozionelos, N., \& Wang, L. 2007. An investigation on the attitudes of Chinese workers towards individually based performance-related reward systems. The International Journal of Human Resource Management, 18(2): 284-302.

Brannen, M. Y. 2004. When Mickey loses face: Recontextualization, semantic fit, and the semiotics of foreignness. Academy of Management Review, 29(4): 593-616.

Brannen, M. Y., \& Thomas, D. C. 2010. Bicultural individuals in organizations: implications and opportunity. International Journal of Cross Cultural Management, 10(1): 5-16.

Brewster, C., Mayrhofer, W., \& Morley, M. (Eds.). 2004. Human resource management in Europe: evidence of convergence? Oxford: Butterworth-Heinemann.

Buckley, P. J. 2002. Is the international business research agenda running out of steam? Journal of International Business Studies, 33(2): 365-373.

Buckley, P. J., Doh, J. P., \& Benischke, M. H. 2017. Towards a renaissance in international business research? Big questions, grand challenges, and the future of IB scholarship. Journal of International Business Studies, 48(9): 1045-1064.

Caligiuri, P. 2012. Cultural agility: building a pipeline of globally successful professionals. San Francisco: Jossey-Bass.

Caligiuri, P. 2021. Build your cultural agility: the nine competencies of successful global professionals. Kogan Page.

Caligiuri, P., \& Tarique, I. 2016. Cultural agility and international assignees' effectiveness in cross-cultural interactions. International Journal of Training and Development, 20(4): 280-289.

Calvano, L. 2008. Multinational corporations and local communities: a critical analysis of conflict. Journal of Business Ethics, 82(4): 793-805.

Cameron, K., \& Quinn, R. 1988. Organizational paradox and transformation. In R. Quinn, \& K. Cameron (Eds.), Paradox and transformation: toward a theory of change in organization and management: 1-18. Pensalcola: Ballinger.

Canato, A., Ravasi, D., \& Phillips, N. 2013. Coerced practice implementation in cases of low cultural fit: cultural change and practice adaptation during the implementation of Six Sigma at 3M. Academy of Management Journal, 56(6): 1724-1753.

Caprar, D. V. 2011. Foreign locals: a cautionary tale on the culture of MNC local employees. Journal of International Business Studies, 42(5): 608-628.

Caprar, D. V., \& Neville, B. A. 2012. "Norming" and "conforming": integrating cultural and institutional explanations for sustainability adoption in business. Journal of Business Ethics, 110(2): 231-245.

Caprar, D. V., Devinney, T. M., Kirkman, B. L., \& Caligiuri, P. 2015. Conceptualizing and measuring culture in international business and management: from challenges to potential solutions. Journal of International Business Studies, 46(9): 1011-1027.

Chang, E. 2006. Individual pay for performance and commitment HR practices in South Korea. Journal of World Business, 41(4): 368-381.

Chatterjee, S., Lubatkin, M. H., Schweiger, D. M., \& Weber, Y. 1992. Cultural differences and shareholder value in related mergers: linking equity and human capital. Strategic Management Journal, 13(5): 319-334. 
Chen, C. C. 1995. New trends in reward allocation preferences: a SINO-U.S. Comparison. Academy of Management Journal, 38(2): 408-428.

Chen, C. C., Chen, X.-P., \& Meindl, J. R. 1998. How can cooperation be fostered? The cultural effects of individualismcollectivism. Academy of Management Review, 23(2): 285-304.

Chen, C. C., Chen, Y.-R., \& Xin, K. 2004. Guanxi practices and trust in management: a procedural justice perspective. Organization Science, 15(2): 200-209.

Chen, G., Sharma, P. N., Edinger, S. K., Shapiro, D. L., \& Farh, J. L. 2011a. Motivating and demotivating forces in teams: crosslevel influences of empowering leadership and relationship conflict. Journal of Applied Psychology, 96(3): 541-557.

Chen, Y., Friedman, R., Yu, E., \& Sun, F. 2011b. Examining the positive and negative effects of guanxi practices: a multi-level analysis of guanxi practices and procedural justice perceptions. Asia Pacific Journal of Management, 28: 715-735.

Chen, C. C., Gaspar, J. P., Friedman, R., Newburry, W., Nippa, M. C., Xin, K., \& Parente, R. 2017. Paradoxical relationships between cultural norms of particularism and attitudes toward relational favoritism: a cultural reflectivity perspective. Journal of Business Ethics, 145(1): 63-79.

Chiang, F. 2005. A critical examination of Hofstede's thesis and its application to international reward management. The International Journal of Human Resource Management, 16(9): 1545-1563.

Chiang, F. F. T., \& Birtch, T. A. 2006. An empirical examination of reward preferences within and across national settings. Management International Review, 46(5): 573-596.

Chiang, F. F. T., \& Birtch, T. A. 2007. The transferability of management practices: examining cross-national differences in reward preferences. Human Relations, 60(9): 1293-1330.

Chiang, F. F. T., \& Birtch, T. A. 2012. The performance implications of financial and non-financial rewards: an Asian Nordic comparison. Journal of Management Studies, 49(3): 538-570.

Colakoglu, S., Allen, M., Miah, K., \& Bird, A. 2016. Highinvestment $H R$ values and firm performance among local firms and U.S. MNCs' subsidiaries in South Asia: a comparative study. The International Journal of Human Resource Management, 27(13): 1426-1447.

Collings, D. G., Mellahi, K., \& Cascio, W. F. 2018. Global talent management and performance in multinational enterprises: a multilevel perspective. Journal of Management, 45(2): 540-566

Collinson, S., \& Wilson, D. C. 2006. Inertia in Japanese organizations: knowledge management routines and failure to innovate. Organization Studies, 27(9): 1359-1387.

Daniels, M. A., \& Greguras, G. J. 2014. Exploring the nature of power distance: implications for micro- and macro-level theories, processes, and outcomes. Journal of Management, 40(5): 1202-1229.

Dansereau, F., Yammarino, F. J., Markham, S. E., Alutto, J. A., Newman, J., \& Dumas, M. 1995. Individualized leadership: a new multiple-level approach. Leadership Quarterly, 6(3): 413-450.

Deci, E. L., \& Ryan, R. M. 2000. The "what" and "why" of goal pursuits: human needs and the self-determination of behavior. Psychological Inquiry, 11(4): 227-268.

Deci, E. L., \& Ryan, R. M. 2002. Handbook of self-determination research. Rochester: University of Rochester Press.

Deci, E. L., Olafsen, A. H., \& Ryan, R. M. 2017. Self-determination theory in work organizations: the state of a science. Annual Review of Organizational Psychology and Organizational Behavior, 4: 19-43.

Delios, A. 2017. The death and rebirth (?) of international business research. Journal of Management Studies, 54(3): 391-397.

DiMaggio, P. J., \& Powell, W. W. 1983. The iron cage revisited: Institutional isomorphism and collective rationality in organizational fields. American Sociological Review, 48(2): 147-160.
Doh, J. P. 2015. From the editor: why we need phenomenonbased research in international business. Journal of World Business, 4(50): 609-611.

Donaldson, L. 2001. The contingency theory of organizations. Sage.

Du, J., \& Choi, J. N. 2010. Pay for performance in emerging markets: insights from China. Journal of International Business Studies, 41(4): 671-689.

Dunphy, D. 1987. Convergence/divergence: a temporal review of the Japanese enterprise and its management. Academy of Management Review, 12(3): 445-459.

Earley, P. C. 1994. Self or group? Cultural effects of training on self-efficacy and performance. Administrative Science Quarterly, 39(1): 89-117.

Earley, P. C., \& Gibson, C. B. 1998. Taking stock in our progress on individualism-collectivism: 100 years of solidarity and community. Journal of Management, 24(3): 265-304.

Edman, J. 2016a. Reconciling the advantages and liabilities of foreignness: towards an identity-based framework. Journal of International Business Studies, 47(6): 674-694.

Edman, J. 2016b. Cultivating foreignness: How organizations maintain and leverage minority identities. Journal of Management Studies, 53(1): 55-88.

Edwards, T., Sánchez-Mangas, R., Jalette, P., Lavelle, J., \& Minbaeva, D. 2016. Global standardization or national differentiation of HRM practices in multinational companies? A comparison of multinationals in five countries. Journal of International Business Studies, 47(8): 997-1021.

Enc, B., \& Adams, F. 1992. Functions and goal directedness. Philosophy of Science, 59(4): 635-654.

Erez, M., \& Earley, P. C. 1987. Comparative analysis of goalsetting strategies across cultures. Journal of Applied Psychology, 72(4): 658-665.

Fadil, P., Segrest-Purkiss, S. L., Hurley-Hanson, A. E., Knudstrup, M., \& Stepina, L. 2004. Distributive justice in Northern Mexico and the US: a cross-cultural comparison. Cross Cultural Management: an International Journal, 11(3): 3-24.

Farndale, E., Brewster, C., Ligthart, P., \& Poutsma, E. 2017. The effects of market economy type and foreign MNE subsidiaries on the convergence and divergence of HRM. Journal of International Business Studies, 48(9): 1065-1086.

Feldman, M. S. 2003. A performative perspective on stability and change in organizational routines. Industrial and Corporate Change, 12(4): 727-752.

Fisher, D. M. 2014. A multilevel cross-cultural examination of role overload and organizational commitment: investigating the interactive effects of context. Journal of Applied Psychology, 99(4): 723-736.

Fock, H., Hui, M. K., Au, K., \& Bond, M. H. 2012. Moderation effects of power distance on the relationship between types of empowerment and employee satisfaction. Journal of CrossCultural Psychology, 44(2): 281-298.

Ford, J. D., \& Ford, L. W. 1995. The role of conversations in producing intentional change in organizations. Academy of Management Review, 20(3): 541-570.

Friedland, R., \& Alford, R. R. 1991. Bringing society back in: symbols, practices, and institutional contradictions. In W. W. Powell, \& P. J. DiMaggio (Eds.), The new institutionalism in organizational analysis: 232-266. Chicago: University of Chicago Press.

Gamble, J. 2006. Introducing western-style HRM practices to China: Shopfloor perceptions in a British multinational. Journal of World Business, 41(4): 328-343.

Gao, M. H. 2013. Culture determines business models: analyzing home depot's failure case in China for international retailers from a communication perspective. Thunderbird International Business Review, 55(2): 173-191.

Gaur, A. S., Delios, A., \& Singh, K. 2007. Institutional environments, staffing strategies, and subsidiary performance. Journal of Management, 33(4): 611-636. 
Geary, J., \& Aguzzoli, R. 2016. Miners, politics and institutional caryatids: accounting for the transfer of HRM practices in the Brazilian multinational enterprise. Journal of International Business Studies, 47: 968-996.

Gelfand, M. J., Nishii, L. H., \& Raver, J. L. 2006. On the nature and importance of cultural tightness-looseness. Journal of Applied Psychology, 91(6): 1225-1244.

George, G., Howard-Grenville, J., Joshi, A., \& Tihanyi, L. 2016. Understanding and tackling societal grand challenges through management research. Academy of Management Journal, 59(6): 1880-1895.

Gerhart, B., \& Fang, M. 2005. National culture and human resource management: assumptions and evidence. The International Journal of Human Resource Management, 16(6): 971-986.

Giacobbe-Miller, J. K., Miller, D. J., Zhang, W., \& Victorov, V. I. 2003. Country and organizational-level adaption to foreign workplace ideologies: a comparative study of distributive justice values in China, Russia and the United States. Journal of International Business Studies, 34(4): 389-406.

Glynn, M. A., Barr, P. S., \& Dacin, M. T. 2000. Pluralism and the problem of variety. Academy of Management Review, 25(4): 725-734.

Goby, V. P. 2015. Financialization and outsourcing in a different guise: the ethical chaos of workforce localization in the United Arab Emirates. Journal of Business Ethics, 131(2): 415-421.

Goerzen, A., Asmussen, C., \& Nielsen, B. 2013. Global cities and multinational enterprise location strategy. Journal of International Business Studies, 44: 427-450.

Gomez-Mejia, L. R., \& Palich, L. E. 1997. Cultural diversity and the performance of multinational firms. Journal of International Business Studies, 28(2): 309-335.

Gong, Y. 2003. Subsidiary staffing in multinational enterprises: agency, resources, and performance. Academy of Management Journal, 46(6): 728-739.

Gong, W. 2009. National culture and global diffusion of business-to-consumer e-commerce. Cross Cultural Management: an International Journal, 16(1): 83-101.

Gonzalez, R. F., \& McMillan, C. 1961. The universality of American management philosophy. Academy of Management Journal, 4(1): 33-41.

Gould, S. J., \& Grein, A. F. 2009. Think glocally, act glocally: A culture-centric comment on Leung, Bhagat, Buchan, Erez and Gibson (2005). Journal of International Business Studies, 40(2): 237-254.

Graves, L., \& Luciano, M. 2013. Self-determination at work: understanding the role of leader-member exchange. Motivation and Emotion, 37(3): 518-536.

Greenwood, R., \& Suddaby, R. 2006. Institutional entrepreneurship in mature fields: the big five accounting firms. Academy of Management Journal, 49(1): 27-48.

Grund, C., \& Westergaard-Nielsen, N. 2008. The dispersion of employees' wage increases and firm performance. Industrial and Labor Relations Review, 61(4): 485-501.

Hambrick, D. C. 2007. The field of management's devotion to theory: too much of a good thing? Academy of Management Journal, 50(6): 1346-1352.

Hannan, M. T., \& Freeman, J. 1977. The population ecology of organizations. American Journal of Sociology, 82(5): 929-964.

Harbison, F. 1959. Management in Japan. In F. Harbison, \& C. A. Myers (Eds.), Management in the industrial world: an international analysis: 249-264. New York: McGraw-Hill.

Hatch, M. J., \& Zilber, T. 2012. Conversation at the border between organizational culture theory and institutional theory. Journal of Management Inquiry, 21(1): 94-97.

He, W., Chen, C. C., \& Zhang, L. 2004. Rewards-allocation preferences of Chinese employees in the new millennium: the effects of ownership reform, collectivism, and goal priority. Organization Science, 15(2): 221-231.

Hoffman, R. C., \& Shipper, F. M. 2012. The impact of managerial skills on employee outcomes: a cross cultural study. The International Journal of Human Resource Management, 23(7): 1414-1435.

Hofstede, G. 1980. Culture's consequences: International differences in work-related values. Thousand Oaks: Sage.

Hofstede, G. 2001. Culture's consequences: comparing values, behaviors, institutions and organizations across nations (2nd ed.). Thousand Oaks: Sage.

Hofstede, G. 2006. What did GLOBE really measure? Researchers' minds versus respondents' minds. Journal of International Business Studies, 37(6): 882-896.

Hofstede, G., Neujien, B., Ohayv, D. D., \& Sanders, G. 1990. Measuring organizational cultures: a qualitative and quantitative study across twenty cases. Administrative Science Quarterly, 35(2): 286-316.

House, R. J., Hanges, P. J., Javidan, M., Dorfman, P. W., \& Gupta, V. (Eds.). 2004. Culture, leadership, and organizations. The GLOBE study of 62 societies. Thousand Oaks: Sage.

Humborstad, S. I. W., Humborstad, B., Whitfield, R., \& Perry, C. 2008. Implementation of empowerment in Chinese high power-distance organizations. The International Journal of Human Resource Management, 19(7): 1349-1364.

Husted, B. W., Montiel, I., \& Christmann, P. 2016. Effects of local legitimacy on certification decisions to global and national CSR standards by multinational subsidiaries and domestic firms. Journal of International Business Studies, 47(3): 382-397.

Hutzschenreuter, T., Voll, J. C., \& Verbeke, A. 2011. The impact of added cultural distance and cultural diversity on international expansion patterns: a Penrosean perspective. Journal of Management Studies, 48(2): 305-329.

Hymer, S. H. 1960/1976. The international operations of national firms: a study of direct foreign investment. MIT Press.

Jackson, G., \& Deeg, R. 2008. Comparing capitalisms: Understanding institutional diversity and its implications for international business. Journal of International Business Studies, 39(4): 540-561.

Jaeger, A. M. 1986. Organization development and national culture: where's the fit? Academy of Management Review, 11(1): 178-190.

Javidan, M., House, R. J., Dorfman, P. W., Hanges, P. J., \& de Luque, M. S. 2006. Conceptualizing and measuring cultures and their consequences: a comparative review of GLOBE's and Hofstede's approaches. Journal of International Business Studies, 37(6): 897-914.

Jiang, F., \& Stening, B. W. 2013. Do indigenous firms incur a liability of localness when operating in their home market? The case of China. Journal of World Business, 48(4): 478-489.

Jiang, Y., Colakoglu, S., Lepak, D. P., Blasi, J. R., \& Kruse, D. L. 2015. Involvement work systems and operational effectiveness: exploring the moderating effect of national power distance. Journal of International Business Studies, 46(3): 332-354.

Joardar, A., \& Wu, S. 2017. Liabilities and benefits: examining the two sides of the foreignness coin from entrepreneurial perspective. International Business Review, 26(6): 1157-1167.

Kabasakal, H., Dastmalchian, A., Karacay, G., \& Bayraktar, S. 2012. Leadership and culture in the MENA region: an analysis of the GLOBE project. Journal of World Business, 47(4): 519-529.

Kanungo, R. N., \& Jaeger, A. M. 1990. Introduction: the need for indigenous management in developing countries. In A. M. Jaeger, \& R. N. Kanungo (Eds.), Management in developing countries: 1-23. London: Routledge.

Kerr, C., Dunlop, J. T., Harbison, F. H., \& Myers, C. A. 1960. Industrialism and industrial man. Boston: Harvard University Press.

Kirkman, B. L., \& Shapiro, D. L. 1997. The impact of cultural values on employee resistance to teams: toward a model of globalized self-managing work team effectiveness. Academy of Management Review, 22(3): 730-757. 
Kirkman, B. L., Lowe, K. B., \& Gibson, C. B. 2006. A quarter century of culture's consequences: a review of empirical research incorporating Hofstede's cultural values framework. Journal of International Business Studies, 37(3): 285-320.

Kostova, T., \& Roth, K. 2002. Adoption of an organizational practice by subsidiaries of multinational corporations: Institutional and relational effects. Academy of Management Journal, 45(1): 215-233.

Kostova, T., Roth, K., \& Dacin, M. T. 2008. Institutional theory in the study of multinational corporations: a critique and new directions. Academy of Management Review, 33(4): 994-1006.

Kraatz, M. S., Flores, R., \& Chandler, D. 2020. The value of values for institutional analysis. Academy of Management Annals, 14(2): 474-512.

Kuhn, T. 2012 [1962]. The structure of scientific revolutions $\left(4^{\text {th }}\right.$ ed.). University of Chicago Press.

Laurent, A. 1986. The cross-cultural puzzle of international human resource management. Human Resource Management, 25(1): 91-102.

Lawrence, P. R., \& Lorsch, J. W. (Eds.). 1986. Organization and environment: managing differentiation and integration. Boston: Harvard Business School Press.

Lawrence, T., Suddaby, R., \& Leca, B. 2011. Institutional work: refocusing institutional studies of organization. Journal of Management Inquiry, 20(1): 52-58.

Lazarova, M., Morley, M., \& Tyson, S. 2008. International comparative studies in human resource management and performance: the CRANET data. International Journal of Human Resource Management, 19(11): 1995-2131.

Lee, H.-J., lijima, Y., \& Reade, C. 2011. Employee preference for performance-related pay: predictors and consequences for organizational citizenship behaviour in a Japanese firm. The International Journal of Human Resource Management, 22(10): 2086-2109.

Leung, K., \& Morris, M. W. 2015. Values, schemas, and norms in the culture-behavior nexus: a situated dynamics framework. Journal of International Business Studies, 46(9): 1028-1050.

Lewis, M. W. 2000. Exploring paradox: toward a more comprehensive guide. Academy of Management Review, 25(4): 760-776.

Li, D., Kreuzbauer, R., Chiu, C., \& Keh, H. T. 2020. Culturally polite communication: enhancing the effectiveness of the localization strategy. Journal of Cross-Cultural Psychology, 51(1): 49-69.

Lowe, K. B., Milliman, J., De Cieri, H., \& Dowling, P. J. 2002. International compensation practices: a ten-country comparative analysis. Human Resource Management, 41(1): 45-66.

Lücke, G., Kostova, T., \& Roth, K. 2014. Multiculturalism from a cognitive perspective: patterns and implications. Journal of International Business Studies, 45(2): 169-190.

Luiz, J. M. 2015. The impact of ethno-linguistic fractionalization on cultural measures: dynamics, endogeneity and modernization. Journal of International Business Studies, 46(9): 1080-1098.

Luo, Y. 2016. Toward a reverse adaptation view in cross-cultural management. Cross Cultural \& Strategic Management, 23(1): 29-41.

Luo, Y. 2020. Adaptive learning in international business. Journal of International Business Studies, 51(9): 1547-1567.

Ma, R., \& Allen, D. G. 2009. Recruiting across cultures: a valuebased model of recruitment. Human Resource Management Review, 19(4): 334-346.

Maddux, W. W., Lu, J. G., Affinito, S. J., \& Galinsky, A. D. 2021. Multicultural experiences: a systematic review and new theoretical framework. Academy of Management Annals, 15(2): 345-376.

Markus, H., \& Nurius, P. 1986. Possible selves. American Psychologist, 41(9): 954-969.

Martin, J. 2002. Organizational culture: mapping the terrain. Thousand Oaks: Sage.
Mayes, B. T., Finney, T. G., Johnson, T. W., Shen, J., \& Yi, L. 2017. The effect of human resource practices on perceived organizational support in the People's Republic of China. The International Journal of Human Resource Management, 28(9): 1261-1290.

Mellahi, K., Budhwar, P. S., \& Li, B. 2010. A study of the relationship between exit, voice, loyalty and neglect and commitment in India. Human Relations, 63(3): 349-369.

Mellahi, K., Frynas, J. G., \& Collings, D. G. 2016. Performance management practices within emerging market multinational enterprises: the case of Brazilian multinationals. The International Journal of Human Resource Management, 27(8): 876-905.

Mendonca, M., \& Kanungo, R. N. 1994. Managing human resources: the issue of cultural fit. Journal of Management Inquiry, 3(2): 189-205.

Meyer, E. 2015. When culture doesn't translate. Harvard Business Review, 93: 66-72.

Meyer, R. E., \& Höllerer, M. A. 2014. Does institutional theory need redirecting? Journal of Management Studies, 51(7): 1221-1233.

Meyer, J. W., \& Rowan, B. 1977. Institutionalized organizations: formal structure as myth and ceremony. American Journal of Sociology, 83(2): 340-363.

Mezias, J. M. 2002. Identifying liabilities of foreignness and strategies to minimize their effects: the case of labor lawsuit judgments in the United States. Strategic Management Journal, 23(3): 229-244.

Morgan, G., Campbell, J., Crouch, C., Pedersen, O. K., \& Whitley, R. 2010. The Oxford handbook of comparative institutional analysis. Oxford: Oxford University Press.

Morgan, G., \& Smircich, L. 1980. The case for qualitative research. Academy of Management Review, 5(4): 491-500.

Morosini, P., Shane, S., \& Singh, H. 1998. National cultural distance and cross-border acquisition performance. Journal of International Business Studies, 29(1): 137-158.

Nachum, L., Zaheer, S., \& Gross, S. 2008. Does it matter where countries are? Proximity to knowledge, markets and resources, and MNE location choices. Management Science, 54(7): 1252-1265.

Nelson, R. E., \& Gopalan, S. 2003. Do organizational cultures replicate national cultures? Isomorphism, rejection and reciprocal opposition in the corporate values of three countries. Organization Studies, 24(7): 1115-1151.

Newman, K. L., \& Nollen, S. D. 1996. Culture and congruence: the fit between management practices and national culture. Journal of International Business Studies, 27(4): 753-779.

Nielsen, B. B., Welch, C., Chidlow, A., Miller, S. R., Aguzzoli, R., Gardner, E., Karafyllia, M., \& Pegoraro, D. 2020. Fifty years of methodological trends in JIBS: why future IB research needs more triangulation. Journal of International Business Studies, 51: 1478-1499.

Nyambegera, S. M., Sparrow, P., \& Daniels, K. 2000. The impact of cultural value orientations on individual HRM preferences in developing countries: lessons from Kenyan organizations. The International Journal of Human Resource Management, 11(4): 639-663.

Oberg, W. 1963. Cross-cultural perspectives on management principles. Academy of Management Journal, 6(2): 129-143.

Ouchi, W. G., \& Jaeger, A. M. 1978. Type Z organization: Stability in the midst of mobility. Academy of Management Review, 3(2): 305-314.

Parnell, J. A. 2010. Propensity for participative decision making in Latin America: Mexico and Peru. The International Journal of Human Resource Management, 21(13): 2323-2338.

Patterson, O. 2014. Making sense of culture. Annual Review of Sociology, 40(1): 1-30.

Pelto, P. 1968. The difference between "tight" and "loose" societies. Transaction, 5: 37-40. 
Peng, A. C., \& Tjosvold, D. 2011. Social face concerns and conflict avoidance of Chinese employees with their Western or Chinese managers. Human Relations, 64(8): 1031-1050.

Perez-Batres, L. A., \& Eden, L. 2008. Is there a liability of localness? How emerging market firms respond to regulatory punctuations. Journal of International Management, 14(3): 232-251.

Poole, M. S., \& Van de Ven, A. H. 1989. Using paradox to build management and organization theories. Academy of Management Review, 14(4): 562-578.

Porter, M. E. 1985. Competitive advantage: creating and sustaining superior performance. New York: Free Press.

Prince, N. R., Prince, J. B., \& Kabst, R. 2020. National culture and incentives: are incentive practices always good? Journal of World Business, 55(3): 1-13.

Pudelko, M., \& Harzing, A.-W. 2007. Country-of-origin, localization, or dominance effect? An empirical investigation of HRM practices in foreign subsidiaries. Human Resource Management, 46(4): 535-559.

Rabl, T., Jayasinghe, M., Gerhart, B., \& Kuhlmann, T. M. 2014. A meta-analysis of country differences in the high-performance work system-business performance relationship: the roles of national culture and managerial discretion. Journal of Applied Psychology, 99(6): 1011-1041.

Ralston, D. A. 2008. The crossvergence perspective: reflections and projections. Journal of International Business Studies, 39: 27-40.

Ralston, D. A., Gustafson, D. J., Cheung, F. M., \& Terpstra, R. H. 1993. Differences in managerial values: a study of U.S., Hong Kong and PRC managers. Journal of International Business Studies, 24(2): 249-275.

Rao, A. N., \& Pearce, J. L. 2016. Should management practice adapt to cultural values? The evidence against power distance adaptation. Cross Cultural \& Strategic Management, 23(2): 257-286.

Rasskazova, E., Ivanova, T., \& Sheldon, K. 2016. Comparing the effects of low-level and high-level worker need-satisfaction: a synthesis of the self-determination and Maslow need theories. Motivation and Emotion, 40: 541-555.

Ritzer, G. 2018. The McDonaldization of society. Thoiusand Oaks: Sage.

Robert, C., Probst, T. M., Martocchio, J. J., Drasgow, F., \& Lawler, J. J. 2000. Empowerment and continuous improvement in the United States, Mexico, Poland, and India: predicting fit on the basis of the dimensions of power distance and individualism. Journal of Applied Psychology, 85(5): 643-658.

Rosenthal, R. 1979. The "file drawer problem" and tolerance for null results. Psychological Bulletin, 86(3): 638-641.

Rosenzweig, P. M., \& Nohria, N. 1994. Influences on human resource management practices in multinational corporations. Journal of International Business Studies, 25(2): 229-251.

Rosenzweig, P. M., \& Singh, J. V. 1991. Organizational environments and the multinational enterprise. Academy of Management Review, 16(2): 340-361.

Ryan, R. M., \& Deci, E. L. 2000. Self-determination theory and the facilitation of intrinsic motivation, social development, and well-being. American Psychologist, 55(1): 68-78.

Salomon, R., \& Wu, Z. 2012. Institutional distance and local isomorphism strategy. Journal of International Business Studies, 43(4): 343-367.

Sarala, R. M., \& Vaara, E. 2010. Cultural differences, convergence, and crossvergence as explanations of knowledge transfer in international acquisitions. Journal of International Business Studies, 41(8): 1365-1390.

Schneiberg, M. 2007. What's on the path? Path dependence, organizational diversity and the problem of institutional change in the US economy, 1900-1950. Socio-Economic Review, 5(1): 47-80.
Schotter, A., \& Beamish, P. W. 2011. General manager staffing and performance in transitional economy subsidiaries. International Studies of Management \& Organization, 41(2): 55-87.

Schuler, R. S., \& Rogovsky, N. 1998. Understanding compensation practice variations across firms: the impact of national culture. Journal of International Business Studies, 29(1): 159-177.

Scott, W. R. 2001. Institutions and organizations. Thousand Oaks: Sage.

Selmer, J. 1996. Expatriate or local bosses? HCN subordinates' preferences in leadership behaviour. The International Journal of Human Resource Management, 7(1): 165-178.

Sethi, D., \& Judge, W. 2009. Reappraising liabilities of foreignness within an integrated perspective of the costs and benefits of doing business abroad. International Business Review, 18(4): 404-416.

Shenkar, O. 2001. Cultural distance revisited: Towards a more rigorous conceptualization and measurement of cultural differences. Journal of International Business Studies, 32(3): 519-535.

Shenkar, O., Tallman, S. B., Wang, H., \& Wu, J. (in press). National culture and international business: a path forward. Journal of International Business Studies.

Shi, W., \& Hoskisson, R. E. 2012. Advantages of foreignness: benefits of creative institutional deviance. Advances in International Management, 25: 99-125.

Siegel, J., Pyun, L., \& Cheon, B. Y. 2019. Multinational firms, labor market discrimination, and the capture of outsider's advantage by exploiting the social divide. Administrative Science Quarterly, 64(2): 370-397.

Singh, J. P. 1990. Managerial culture and work-related values in India. Organization Studies, 11(1): 075-101.

Slife, B. D., \& Williams, R. N. 1995. What's behind the research? Discovering hidden assumptions in the behavioral sciences. Thousand Oaks: Sage.

Smith, P. B. 2006. When elephants fight, the grass gets trampled: the GLOBE and Hofstede projects. Journal of International Business Studies, 37(6): 915-921.

Stahl, G. K., \& Tung, R. L. 2015. Towards a more balanced treatment of culture in international business studies: the need for positive cross-cultural scholarship. Journal of International Business Studies, 46(4): 391-414.

Stahl, G. K., Tung, R. L., Kostova, T., \& Zellmer-Bruhn, M. 2016. Widening the lens: rethinking distance, diversity, and foreignness in international business research through positive organizational scholarship. Journal of International Business Studies, 47(6): 621-630.

Stahl, G. K., Miska, C., Lee, H.-J., \& De Luque, M. S. 2017. The upside of cultural differences: towards a more balanced treatment of culture in cross-cultural management research. Cross Cultural \& Strategic Management, 24(1): 2-12.

Starbuck, W. H. 2003. Turning lemons into lemonade: where is the value in peer reviews? Journal of Management Inquiry, 12(4): 344-351.

Suddaby, R. 2010. Challenges for Institutional theory. Journal of Management Inquiry, 19(1): 14-20.

Szkudlarek, B., McNett, J., Romani, L., \& Lane, H. 2013. The past, present, and future of cross-cultural management education: the educators' perspective. Academy of Management Learning \& Education, 12(3): 477-493.

Taras, V., Kirkman, B. L., \& Steel, P. 2010. Examining the impact of culture's consequences: a three-decade, multi-level, metaanalytic review of Hofstede's cultural value dimensions. Journal of Applied Psychology, 95(3): 405-439.

Taras, V., Steel, P., \& Kirkman, B. L. 2016. Does country equal culture? Beyond geography in the search for cultural boundaries. Management International Review, 56(4): 455-487.

Taussig, M. 2017. Foreignness as both a global asset and a local liability: how host country idiosyncrasies and business activities matter. Journal of International Business Studies, 48(4): 498-522. 
Tregaskis, O., \& Brewster, C. 2006. Converging or diverging? A comparative analysis of trends in contingent employment practice in Europe over a decade. Journal of International Business Studies, 37(1): 111-126.

Triandis, H. C. 1989. The self and social behavior in differing cultural contexts. Psychological Review, 96(3): 506-520.

Tsui, A. S., Nifadkar, S., \& Ou, A. Y. 2007. Cross-national, crosscultural organizational behavior research: advances, gaps, and recommendations. Journal of Management, 33(3): 426-478.

Tung, R. L. 2008. The cross-cultural research imperative: the need to balance cross-national and intra-national diversity. Journal of International Business Studies, 39(1): 41-46.

Tung, R. L., \& Stahl, G. K. 2018. The tortuous evolution of the role of culture in IB research: what we know, what we don't know, and where we are headed. Journal of International Business Studies, 49(1): 1167-1189.

Un, C. A. 2011. The advantage of foreignness in innovation. Strategic Management Journal, 32(11): 1232-1242.

Un, C. A. 2016. The liability of localness in innovation. Journal of International Business Studies, 47(1): 44-67.

Vaara, E., Sarala, R., Stahl, G. K., \& Björkman, I. 2012. The impact of organizational and national cultural differences on social conflict and knowledge transfer in international acquisitions. Journal of Management Studies, 49(1): 1-27.

Van de Ven, A. H. 1976. On the nature, formation, and maintenance of relations among organizations. Academy of Management Review, 1(4): 24-36.

Van de Ven, A. H., \& Poole, M. S. 1995. Explaining development and change in organizations. Academy of Management Review, 20(3): 510-540.

Varma, A., Toh, S. M., \& Budhwar, P. 2006. A new perspective on the female expatriate experience: the role of host country national categorization. Journal of World Business, 41(2): 112-120.

Venaik, S., \& Midgley, D. 2015. Mindscapes across landscapes: archetypes of transnational and subnational culture. Journal of International Business Studies, 46(9): 1051-1079.

Verbeke, A., Coeurderoy, R., \& Matt, T. 2018. The future of international business research on corporate globalization that never was. Journal of International Business Studies, 49(9): 1101-1112.

Vo, A., \& Hannif, Z. N. 2013. The reception of Anglo leadership styles in a transforming society: the case of American companies in Vietnam. The International Journal of Human Resource Management, 24(18): 3534-3551.

Vogel, E. F. 1979. Japan as number one: lessons for America. Boston: Harvard University Press.

Von Glinow, M. A., Drost, E. A., \& Teagarden, M. B. 2002. Converging on HRM best practices: lessons learned from a globally distributed consortium on theory and practice. Human Resource Management Review, 41(1): 123-140.

Warren, D. E., Dunfee, T. W., \& Li, N. 2004. Social exchange in China: the double-edged sword of guanxi. Journal of Business Ethics, 55(4): 353-370.

Watzlawick, P., Weakland, J., \& Fisch, R. 1974. Principles of problem formation and problem resolution. London: Norton \& Company Inc.

Westney, D. E. 1993. Institutional theory and the MNC. In S. Ghoshal, \& D. E. Westney (Eds.), Organization theory and the MNC:53-76. New York: St. Martin's Press.

Witt, M. A. 2008. Crossvergence 10 years on: impact and further potential. Journal of International Business Studies, 39(1): 47-52.
Yanadori, Y., \& Cui, V. 2013. Creating incentives for innovation? The relationship between pay dispersion in R\&D groups and firm innovation performance. Strategic Management Journal, 34(12): 1502-1511.

Yang, F., Huang, X., Tang, D., Yang, J., \& Wu, L. 2021. How guanxi HRM practice relates to emotional exhaustion and job performance: the moderating role of individual pay for performance. The International Journal of Human Resource Management, 32(11): 2493-2518.

Yousfi, H. 2014. Rethinking Hybridity in Postcolonial Contexts: What Changes and What Persists? The Tunisian case of Poulina's managers. Organization Studies, 35(3): 393-421.

Zaheer, S. 1995. Overcoming the liability of foreignness. Academy of Management Journal, 38(2): 341-363.

Zhu, C. J., Cooper, B., De Cieri, H., \& Dowling, P. J. 2005. A problematic transition to a strategic role: human resource management in industrial enterprises in China. The International Journal of Human Resource Management, 16(4): 513-531.

\section{ABOUT THE AUTHORS}

Dan V. Caprar is an Associate Professor at the University of Sydney Business School, Australia. His research, teaching, and consulting are focused on culture, identity, and leadership. Before receiving his MBA and PhD from the University of Iowa, Dan worked in a range of consulting and managerial roles in business, NGOs, and government organizations in Romania, UK, and USA.

Sunghoon Kim is an Associate Professor at The University of Sydney Business School. He received his $\mathrm{PhD}$ from Cornell University. His main research interests are strategic human resource management and comparative employment relationships, particularly in the context of emerging economies. He is currently serving as an Associate Editor of Human Resource Management.

Benjamin W. Walker is a Lecturer in the School of Management at Victoria University of Wellington, New Zealand. His core research explores the reciprocal relationships between identity, motivation, and job performance. Other research interests include culture, expertise, and remote work. Ben is also a passionate educator, and currently coordinates the Introduction to Management course at Victoria University of Wellington.

Paula Caligiuri is a D'Amore-McKim School of Business Distinguished Professor in International 
Business at Northeastern University (USA). She researches and consults in expatriate management, global leadership development, and cultural agility. Paula was a semi-finalist for the 2021 Forbes "50 over 50" for co-founding a public benefit corporation, Skiilify, to improve cultural understanding. She holds a PhD in organizational psychology from Penn State University.

Publisher's Note Springer Nature remains neutral with regard to jurisdictional claims in published maps and institutional affiliations.

Accepted by Becky Reuber, Area Editor, 27 September 2021. This article has been with the authors for one revision. 